\title{
Willingness to Pay for Urban Heat Island Mitigation: A Case Study of Singapore
}

\section{Journal Article}

Author(s):

Borzino, Natalia; Chng, Samuel; Mughal, Muhammad Omer; Schubert, Renate

Publication date:

2020-07

Permanent link:

https://doi.org/10.3929/ethz-b-000424536

Rights / license:

Creative Commons Attribution 4.0 International

Originally published in:

Climate 8(7), https://doi.org/10.3390/cli8070082 
Willingness to Pay for Urban Heat Island Mitigation: A Case Study of Singapore

\author{
Natalia Borzino ${ }^{1, *(\mathbb{D}}$, Samuel Chng ${ }^{2}\left(\mathbb{D}\right.$, Muhammad Omer Mughal ${ }^{1}\left(\mathbb{D}\right.$ and Renate Schubert ${ }^{1,3}$ \\ 1 Singapore-ETH Centre, 1 Create Way, CREATE Tower, \#06-01, Singapore 138602, Singapore; \\ mughal@arch.ethz.ch (M.O.M.); schubert@econ.gess.ethz.ch (R.S.) \\ 2 Lee Kuan Yew Centre for Innovative Cities, Singapore University of Technology and Design, 8 Somapah \\ Road, Singapore 487372, Singapore; samuel_chng@sutd.edu.sg \\ 3 Department of Humanities, Social and Political Sciences, Chair of Economics, ETH-Zurich, \\ 8092 Zürich, Switzerland \\ * Correspondence: natalia.borzino@frs.ethz.ch
}

Received: 24 May 2020; Accepted: 19 June 2020; Published: 27 June 2020

check for updates

\begin{abstract}
In many countries, urban heat island (UHI) effects come along with urbanization in metropolitan areas. They have relevant adverse effects on the health and wellbeing of citizens. Singapore is strongly affected by UHI. In this study, we assess Singaporeans' willingness to pay (WTP) for UHI mitigation by implementing a contingent valuation analysis. Specifically, we employ a double-bounded dichotomous survey design on a representative sample of 1822 online respondents. We find that Singaporeans are willing to sacrifice on average $0.43 \%$ of their annual income to mitigate UHI. The total WTP for mitigation strategies among Singapore citizens and permanent residents is estimated at SGD $\$ 783.08$ million per year, the equivalent of USD $\$ 563.80$ per year. Our findings suggest that there is a positive and significant relationship between the size of UHI effects and the citizens' WTP. People living in the region with the highest intensity of UHI are willing to pay 3.09 times more than those living in the region with the lowest UHI intensity. Furthermore, demographic and socio-economic characteristics are significant determinants of Singaporeans' WTP. The WTP increases with income and education but decreases with age. Students, men, and people with children are willing to pay more. Additional analyses show that the level of UHI awareness, positive attitudes towards UHI mitigation strategies as well as preferences for outdoor activities are positively correlated with the WTP. Our findings suggest that citizens are aware of the impacts of UHI and support UHI mitigation measures to be financed by their taxes. Policy interventions to promote UHI-related education and disseminating UHI-related information might increase the support of UHI mitigation policies.
\end{abstract}

Keywords: urban heat island (UHI) effects; double-bounded contingent valuation method; willingness to pay; UHI awareness and attitudes; UHI exposure; spatial analysis

\title{
1. Introduction
}

The urban heat island (UHI) effect in metropolitan areas means that certain areas of cities are significantly warmer than the surrounding areas [1-3]. Higher levels of anthropogenic heat, reduced urban vegetation, and very dense settlement structures without wind corridors are identified as important reasons for the UHI effect. Besides, the UHI effect seems to be related to urban haze pollution (i.e., smog and particle [PM2.5] pollution). UHI is closely related to the city size, population density, energy consumption, and building density and it is reported to cause serious impacts on a population's health and wellbeing [4-10]. It lowers workers' productivity, hereby causing negative economic consequences [11]. The UHI effect seems to raise energy consumption due to a higher usage of air 
conditioning [12-17]. This may result in increased electricity consumption from fossil fuels and hence in a deteriorated air quality and in increased greenhouse gas emissions [18-20].

Singapore underwent a rapid development over the past few decades and the UHI effect is one of the accumulated consequences caused by the urbanization [21]. The fast pace of urbanization diminished the density of forested coverage in Singapore. From the original lowland tropical rainforest that covered the island almost entirely in 1819 , only $0.28 \%$ of the $712 \mathrm{~km}^{2}$ forested area remained by 2012 [21], decreasing even more to $0.23 \%$ by 2015 - which is the lowest amount of originally forested areas left intact among Southeast Asian countries [21,22]. The current UHI effect is remarkably big. Temperature differences peak approximately six hours after sunset with a maximum of $7{ }^{\circ} \mathrm{C}$ difference observed at the Central Business District (CBD) compared with the Natural Reservoir area (baseline) located at the north of the island at the same time [23]. In Singapore, the size of the UHI effect varies between areas, depending on the geographical and urban characteristics of the areas. More vegetation increases moisture and evotranspiration, hence decreasing air temperatures. In the same line, the effects of the sea breeze, of rainfall, and of building height to street width matter for the size of the UHI effect in a specific area [24].

Singapore aims at mitigating the UHI effect to increase the population's wellbeing [25,26]. A catalogue with eighty mitigation strategies has been compiled [27]. Some of the strategies have already been implemented or are esteemed to be beneficial in any case [27]. Various studies have assessed and demonstrated the effectiveness of different strategies for mitigating the UHI effect in Singapore, including green roofs, green facades and greenery $[28,29]$, vertical greenery $[30,31]$, and green pavement [30].

While the Singaporean government has been implementing UHI mitigation strategies across the entire country, the magnitude of positive impacts on the population's well-being resulting from such investments remains unclear. Furthermore, it is an open question how much of the taxes they pay, Singaporeans would be willing to invest into UHI mitigating measures and on which factors the respective amounts depend. An informed decision making would require that citizens are able to assess the (net) benefits of the respective measures. Increasing citizens' awareness of UHI related costs and benefits could be a first step [32]. In addition, policy-makers should take into account the public assessment and the public acceptance of UHI mitigation measures [33,34].

Willingness to pay (WTP) refers to the maximum willingness to pay for a good or service. UHI mitigation could be such a good. In this paper, we elicit the citizens' WTP for UHI mitigation measures. Based on this, we can indicate the degree to which citizens are willing to contribute to obtaining benefits from the respective measures. Theoretically, the WTP corresponds to the perceived wellbeing when urban heat is mitigated and outdoor thermal comfort is improved as a consequence. At the same time, the WTP represents the level of damage citizens perceive if heat is not mitigated.

In this paper, we use a multidisciplinary approach to assess and explain Singaporeans' WTP for UHI mitigation. On the one side, we refer to the contingent valuation method (CVM) that is widely used to valuate non-market goods like, for instance, UHI mitigation [35]. This method is a specific application of the stated preference (SP) methodology, relying on direct questioning of people to elicit their WTP for a particular good or a service. On the other side, we use a weather research and forecasting (WRF) model, specifically the multilayer urban canopy model (MLUCM), to quantify the UHI effect in different parts of Singapore. By combining these two approaches, we will be able to analyze the relationship between citizens' WTP for UHI mitigation and several explanatory factors, including the UHI intensity in different residential parts of Singapore. Two recent studies use such spatial analyses to relate the effects of UHI to either residents' electricity consumption [36]; residents' income at the neighborhood scale [37] and population vulnerability to heat-related health risks due to heat exposure [38]. Both studies emphasize that spatial analyses are relevant in order to take into account the intra-urban UHI variability and its respective impacts on the well-being of a population.

The principal aims of this paper are hence to explore: (1) the WTP of Singaporeans and permanent residents in Singapore for the implementation of UHI mitigation strategies; and (2) the key determinants 
of the elicited WTP, i.e., demographic and socio-economic factors, knowledge and information, attitudes, relevance of being outdoors according to the prevalent lifestyles, as well the UHI intensity in different residential regions.

The remainder of this paper is structured as follows. Section 2 explains the research methods; Section 3 describes the contingent valuation model; Section 4 evaluates the results; Section 5 presents a discussion of the results and Section 6 concludes with policy recommendations and directions for future research.

\section{Research Methods}

In this study, we use a multidisciplinary approach. On the one side, we use the contingent valuation method (CVM), which is widely used in economics to measure the WTP. In our case, we measure Singaporeans' and permanent residents' WTP for UHI mitigation. On the other side, we rely on weather models to assess the UHI intensity in different parts of Singapore. The UHI intensity is defined in [39] as the temperature difference between urban and rural places (or areas). These two methods are applied first separately and then combined through a spatial analysis.

\subsection{UHI Assessment}

Before describing the methodology used in the UHI assessment of Singapore, we describe the study area. The island of Singapore is located just north of equator, between $1^{\circ} 09^{\prime} \mathrm{N}$ to $1^{\circ} 29^{\prime} \mathrm{N}$, and $103^{\circ} 36^{\prime}$ E to $104^{\circ} 25^{\prime} \mathrm{E}$, at the southern tip of Peninsula Malaysia (see Figure 1). It is considered tropical with a typical equatorial wet climate. The mean daily temperature minima is in the range of $23-26^{\circ} \mathrm{C}$ and mean daily maxima between $31-34^{\circ} \mathrm{C}$ [23]. The monthly mean temperature range is $26-28^{\circ} \mathrm{C}$ and the annual rainfall is $\sim 2300 \mathrm{~mm}$ [23]. Singapore's climate is characterized by the northeast and southwest monsoon seasons, separated by two short inter-monsoon periods. The southwest monsoon (June to September) is a relatively drier period while the Northeast monsoon season (December to March) comes with high monthly rainfall and stronger winds [23]. The urban thermal environment is mostly affected by the changes in the landscape, i.e., urbanization and industrialization [23].

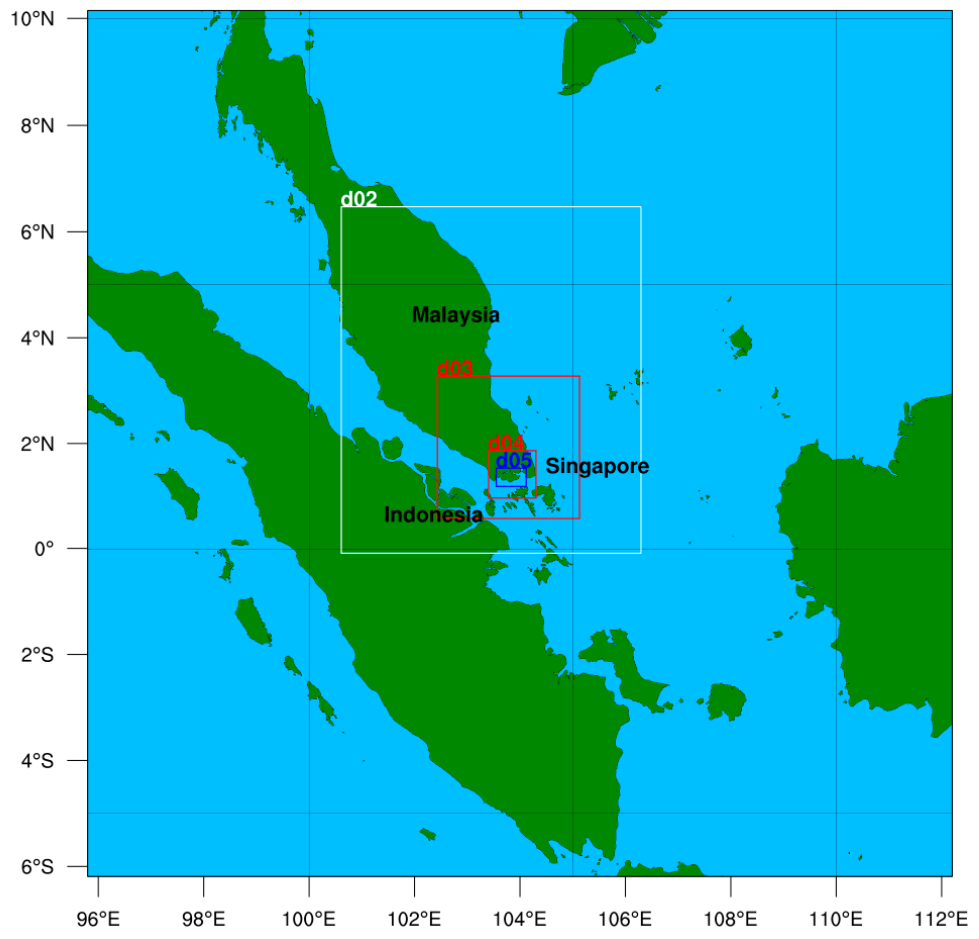

Figure 1. Location of Singapore. Configuration from weather research and forecasting (WRF) model simulations (Source: Mughal [24]). 
Our UHI assessment for different parts of Singapore follows the methodology from [24]. There are few studies calculating the UHI intensity in tropical cities (e.g., [40-42]) using multilayer urban canopy models. However, the cities explored with such models do not have the urban heterogeneity that Singapore presents. [24] assessed the UHI intensity for Singapore, making this work our main reference in this UHI assessment. The authors based their analysis on measurements from 2016 and found out that Singapore's canopy layer UHI intensity can reach up to $\sim 5^{\circ} \mathrm{C}$ in compact areas during the nights. The local climate zone (LCZ) map of Singapore was used to consider land use data and to explore the intra-urban variability of the urban thermal environment. The LCZ is a classification scheme [43] that comprises 17 zones based on properties of surface structure (i.e., building and tree height and density) and surface cover (i.e., pervious vs. impervious). Out of these 10 are urban while 7 are rural. Singapore contains all $10 \mathrm{LCZs}$ according to our calculation. [24] used weather research and forecasting (WRF) model's multilayer urban canopy model (MLUCM) coupled with the building effect parametrization (BEP) and building energy model (BEM). The multilayer urban canopy model using BEP provides a detailed description of the urban environment and morphology to the WRF model, while BEM provides the information about the anthropogenic heat exhausted from the air conditioning systems installed in buildings. The word parameterization refers to mathematical representation of the building's geometry instead of the actual physical existence in the model.

Following [24], we considered an all-green scenario to evaluate Singapore's UHI intensity (see [24] for a full description of the all-green scenario for Singapore). This scenario is a hypothetical one, created by replacing land use, including buildings and human activity in the area, with a scenario with "no" buildings and "no" human activity. This was done in order to establish a rural reference site against which measurements of UHI can be done. [44] explained that calculating the difference in $2 \mathrm{~m}$ height (i.e., pedestrian level) air temperature between the existing situation and the rural scenario as reference (i.e., urban increment) is the most suitable way to measure the UHI intensity. According to the authors, this method is effective to avoid the effects of sea breezes, cloud impacts, and topography in the model. This also indicates the maximum potential for a UHI reduction. Another important advantage of using air temperature to estimate the UHI intensity (instead of other methods such as the surface layer UHI based on surface temperature and remote sensing) is that air temperature is more strongly coupled with heat stress. Therefore, it helps to effectively assess the spatial distribution of heat-related risks for the urban population.

Based on this methodology, we evaluated the spatial variation of UHI intensity across Singapore. To create reasonable sub-sections of Singapore, we used Singapore's postal district segregation. This segregation comprises 5 regions: (1) Central Region; (2) North Region; (3) West Region; (4) Northeast Region, and (5) East Region. We only considered the residential areas in each of these regions. Industrial areas (with high building surface fractions) or areas with minimal (or no) urban dwellings as well as densely forested areas and urban parks were excluded from our analysis.

\subsection{WTP Assessment}

There are three commonly used methods to value non-market goods and services: hedonic pricing, the travel costs method, and the contingent valuation method [45]. Hedonic pricing infers the value of non-market goods from the prices of market goods (e.g., the value of nearby parkland is inferred from prices for private houses). The travel costs method infers the value of a non-market good (e.g., a national park) from the costs incurred by individuals travelling to obtain the good. The third method, the contingent valuation method (CVM), is a survey-based evaluation method explicitly asking for people's maximum willingness to pay for environmental goods and services [46]. This method can be considered as suitable for estimating the perceived increase in well-being created by UHI mitigation measures and hence the value attributed to these measures or the willingness to pay for UHI reducing measures [32,33].

In our study, we estimate Singaporeans' and permanent residents' willingness to pay (WTP) for UHI mitigation in Singapore through the CVM. Theoretically, the amount of money respondents agree 
to pay for UHI mitigation is equal to the welfare they obtain from improvements of their outdoor thermal comfort $[32,33,45,47]$.

The CVM has received criticism since the results can be unduly influenced by the survey design and by the way in which the respective questions are drafted [48]. We tried to minimize the potential biases by relating our survey questions to a tangible good, i.e., to the guarantee of the implementation of the respective mitigation measures for one year. We assumed that Singapore citizens and permanent residents could easily relate to this.

For the WTP elicitation, we used the double-bounded dichotomous contingent valuation (DBDCV) method, which provides very conservative WTP estimates [49]. Indeed, compared with the other commonly used formats such as single-bounded dichotomous choice models (SBDC) or open-ended surveys, the DBDCV method provides much more conservative WTP estimates [50]. Furthermore, this method a high level of consistency in responses [51] as well as a high statistical efficiency [52].

In our DBDCV based survey, we asked the participants to respond "yes" or "no" if asked to hypothetically contribute to a mandatory UHI mitigation fund. Each adult Singaporean and permanent resident would have to pay a fixed fraction of their annual incomes to this fund, which would guarantee that the government uses the money to implement the indicated UHI mitigation measures. The questions were worded in a realistic and tangible way. The time frame given in the questions was one year, i.e., potential contributions to the fund and the implementation of UHI mitigating measures were aligned time-wise.

\subsubsection{WTP Payment Vehicle}

In order to make sure that respondents reveal the true payment intentions, we use a specific payment medium. According to [53] a payment medium with a mandatory feature can effectively reduce the free-riding and over-pledging of respondents. In our study, we used the personal income tax as payment "vehicle" since Singaporeans and permanent residents are familiar with this medium [54]. The acceptance of this payment vehicle was tested and confirmed during our pilot study.

\subsubsection{Study Design and Protocol}

In our study, we implemented an online survey in Singapore between September and November, 2019. We obtained the IRB approval from ETH Zurich before the implementation of our survey (see Supplementary Materials, survey questionnaire S1). We had 1822 respondents with valid answers, whose WTP for UHI mitigation was elicited. Any participation was voluntary and based on an opt-in principle. In addition to the WTP, demographic and socio-economic characteristics as well as information about the respondents' level of awareness of need for UHI mitigation measures, their level of attitudes towards UHI mitigation and their outdoor preferences were collected. The purpose was to evaluate whether, and to what extent, these attributes determine individual WTP values.

The study collected the 1822 responses from a sample of Singaporeans and permanent residents who have lived in Singapore for at least 2 years and were older than 20 years. The sample was representative for the Singaporean population with respect to gender, age ( 5 brackets), and income (15 brackets) (see Table 1 for a description of our sample in Column 1 and a comparison with Singapore's population in Column 2). People aged 60 years and above are underrepresented in our sample. We incorporated income brackets options into our survey to increase the validity of the data. Hesitant respondents may become more likely to offer a rough indication of their earnings, so that income information for these individuals is no longer missing or reported in a false category [55]. 
Table 1. Representative sample in terms of gender, age, and annual income. Comparison between the sample and the Singapore population.

\begin{tabular}{ccc}
\hline & Percentage of Respondents ${ }^{\mathbf{1}}$ & ${\text { Percentage of Population }{ }^{\mathbf{2}}}$ \\
\hline & Gender & \\
\hline Male & $49.95 \%(\mathrm{n}=910)$ & $51.09 \%$ \\
Female & $49.34 \%(\mathrm{n}=899)$ & $48.90 \%$ \\
Prefer not to say & $0.71 \%(\mathrm{n}=13)$ & \\
\hline \multicolumn{3}{c}{ Age distribution } \\
\hline 20 to 29 & $21.34 \%(\mathrm{n}=389)$ & $17 \%$ \\
30 to 39 & $26.39 \%(\mathrm{n}=481)$ & $18 \%$ \\
40 to 49 & $23.86 \%(\mathrm{n}=435)$ & $20 \%$ \\
50 to 59 & $21.45 \%(\mathrm{n}=391)$ & $20 \%$ \\
60 and above & $6.97 \%(\mathrm{n}=127)$ & $25 \%$ \\
\hline & $\mathrm{Gross}$ monthly income & $3.3 \%$ \\
\hline No income & $2.36 \%(\mathrm{n}=43)$ & $7.5 \%$ \\
$<2000$ & $8.6 \%(\mathrm{n}=157)$ & $16.1 \%$ \\
2000 to 4999 & $18.01 \%(\mathrm{n}=328)$ & $26.3 \%$ \\
5000 to 9999 & $28.54 \%(\mathrm{n}=520)$ & $17.5 \%$ \\
10,000 to 13,999 & $16.35 \%(\mathrm{n}=298)$ & $21.9 \%$ \\
14,000 and above & $26.12 \%(\mathrm{n}=476)$ & \\
\hline
\end{tabular}

${ }^{1}$ Note: 13 respondent preferred not to declare their gender; all our respondents declared age and income. ${ }^{2}$ Source: Data from the Department of Statistics of Singapore https://www.singstat.gov.sg/.

We decided to not conduct the survey in historically very hot months of the year (i.e., April and May) to avoid an overestimation of WTP values due to recency and primacy effects when experiencing seasonally high temperatures. We conducted the study therefore between September and November, i.e., during the Southwest Monsoon season and Inter-Monsoon period. This period is just in the middle between the warmer season (i.e., May and June) and cooler season (i.e., December and January) in Singapore.

The survey protocol followed this structure:

1. We obtained written consent from the respondents prior to the survey. However, participants could withdraw from the survey at any time without giving any reason, and all the data collected from those participants were discarded.

2. Respondents' demographic characteristics (age, gender, education, etc.), their socio-economic attributes (income and employment), as well as information on their level of awareness of need for UHI mitigation, level of attitudes towards UHI mitigation and outdoor preferences were asked for in a questionnaire and collected. The demographic and socio-economic information was used to build up citizen profiles with differing WTPs. No identifiable information was collected. For all questions, which were deemed sensitive, we provided an, "I prefer not to answer" option so that respondents had a way to bypass the question. This also helped to lower the number of inaccurate or missing responses, resulting in a higher validity and accuracy of the data collected.

3. After having answered the questionnaire, a short description summarizing the UHI situation in Singapore as well as an illustrative image of the different temperatures across Singapore were presented to the respondents. They also received information on the meaning of UHI and a map from Singapore showing different UHI values in different regions [24] (see Figure 2). Specifically, we informed participants that "The urban heat island effect is the local temperature increase due to human activity and urbanization. The image shows the current urban heat island effect in Singapore. The brighter areas represent regions in Singapore that experience higher air temperature due to human activity and urbanization. The regions in red experience up to $4.2^{\circ} \mathrm{C}$ 
increase in air temperature in comparison to regions in blue. For example, Orchard Road is $4.2{ }^{\circ} \mathrm{C}$ hotter than the Bukit Timah Nature Reserve".

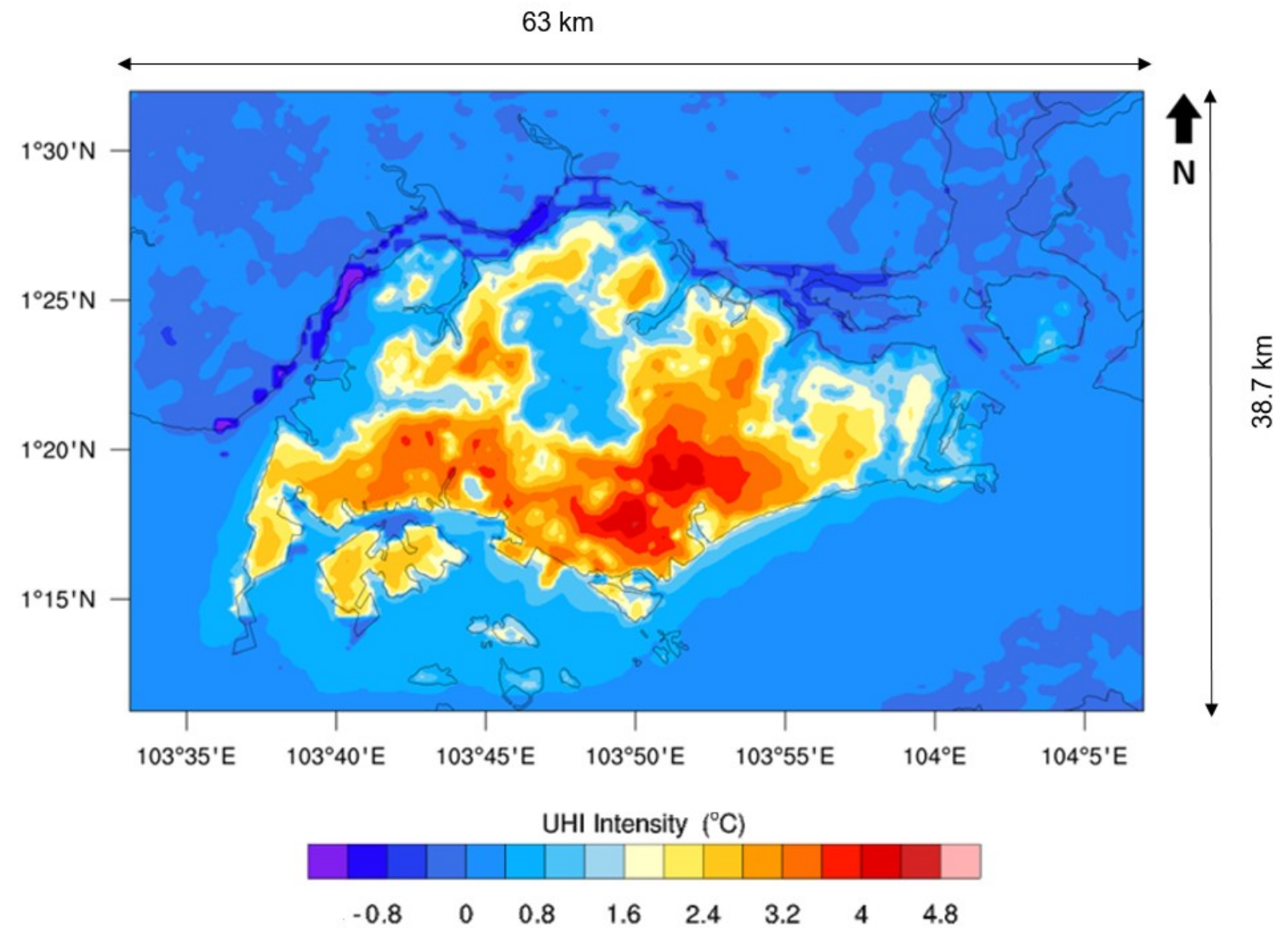

Figure 2. Map of the Urban Heat Island(UHI) situation in Singapore presented to the respondents. (average difference in 2-m temperature between "Control" and "AllGreen" case at 04:00 LT, April 2016-Source: Mughal et al., 2019) [24].

1. First Bid: We then asked the respondents whether (answering "YES") or not (answering "NO") they would support a policy that obliges all people living permanently in Singapore to contribute to a mitigation strategy fund during one year. They were confronted with differing specific percentages of their incomes that they would be asked to contribute. The percentages presented in the questionnaires varied randomly between seven possible bid-bundles previously established as plausible in a pilot study (see Table 2). To facilitate the understanding of the corresponding percentage values, the respondents were also presented with a numerical calculation of what this percentage $\left(X_{1}\right)$ of their annual income would be in Singapore Dollars. The design of the bids was calculated based on the WTP results from a pilot study, which we did with a representative sample of 200 respondents in Singapore in the month before starting the main survey. The respondents in the pilot study were exposed to the same main survey as the one presented here, but with an open-ended contingent valuation format. We trimmed $10 \%$ off both tails of the bid distribution and selected seven bid combinations from the remaining distribution for our main survey. The methodology for selecting the final seven bid combinations followed the seminal work of Cooper [56], wherein the optimal bid design is the one that minimizes the square errors. The main objective of the pilot study was to get and use the bid distribution to create an unbiased bid design for the main survey, following the methodology described in [56]. 
Table 2. Bid design for our Double Bounded Dichotomous Contingent Valuation (DBDCV) study.

\begin{tabular}{cccccccc}
\hline & \multicolumn{7}{c}{ Bid Bundles } \\
\hline Random Number & $\mathbf{1}$ & $\mathbf{2}$ & $\mathbf{3}$ & $\mathbf{4}$ & $\mathbf{5}$ & $\mathbf{6}$ & $\mathbf{7}$ \\
\hline First bid $\left(\mathrm{X}_{1}\right)$ & $0.10 \%$ & $0.30 \%$ & $0.50 \%$ & $1.0 \%$ & $1.50 \%$ & $3.0 \%$ & $4.50 \%$ \\
Second bid $\left(\mathrm{X}_{\text {high }}\right)$ & $0.30 \%$ & $0.50 \%$ & $1.00 \%$ & $1.50 \%$ & $3.0 \%$ & $4.50 \%$ & $5.50 \%$ \\
Second bid $\left(\mathrm{X}_{\text {low }}\right)$ & $0.05 \%$ & $0.10 \%$ & $0.30 \%$ & $0.50 \%$ & $1.0 \%$ & $1.50 \%$ & $3.0 \%$ \\
\hline
\end{tabular}

2. Second bid: If a respondent answered "YES" to the first bid, the respondent was then asked to respond to the same question again but with a higher bid value $\left(X_{\text {high }}\right)$ (see Table 2$)$. If a respondent answered "NO" to the first ID, the respondent was then presented with a lower second bid $\left(\mathrm{X}_{\text {low }}\right)$. Hence, the two consecutive questions were presented in a decision tree with four different outcomes. Figure 3 displays the flowchart and illustrates steps 4 and 5 of this protocol.

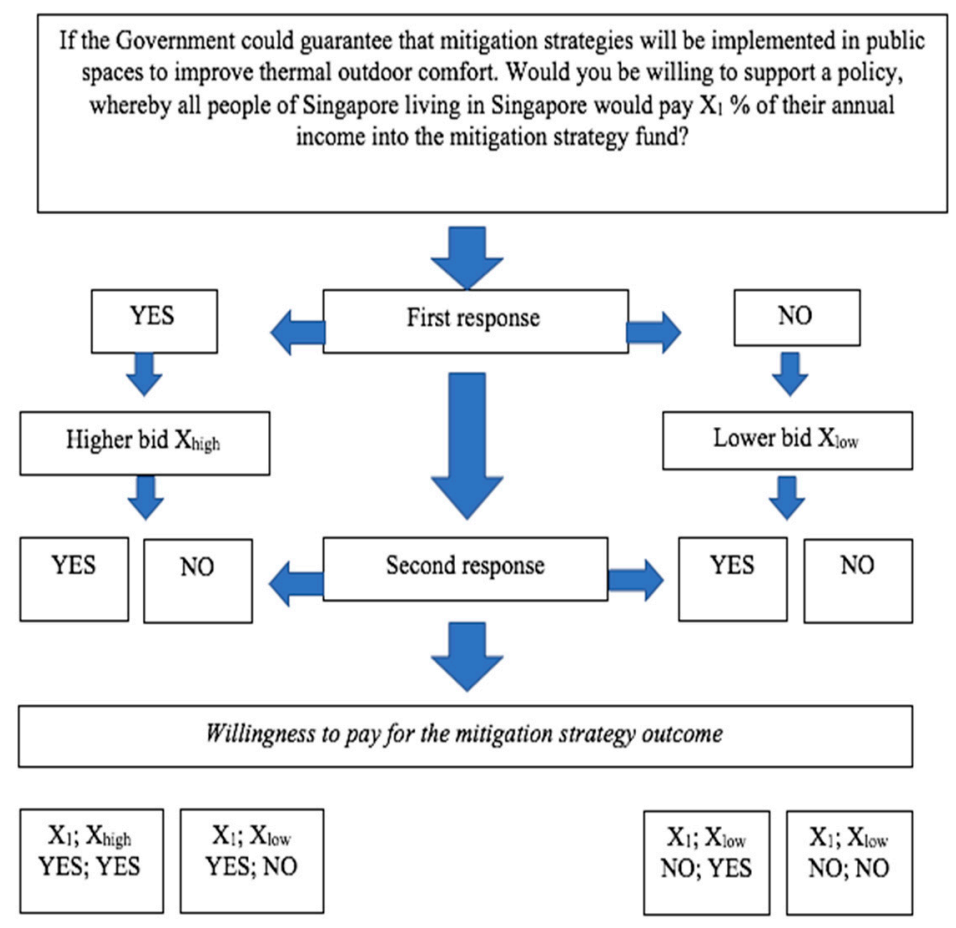

Figure 3. Decision tree of our double-bounded dichotomous choice survey. The bid values $X_{1}, X_{\text {High }}$, and $\mathrm{X}_{\mathrm{Low}}$ were randomly varied across the questionnaires following Table 2.

Accomplishing step 5 of the protocol implies one bid-bundle with three bids values for each respondent (i.e., $X_{1}, X_{\text {high }}$ and $X_{\text {low }}$ ), with the bid-bundle being randomly allocated following Table 2 . Furthermore, we know the outcome from the decisions made by each respondent (i.e., "YES-YES", "YES-NO", "NO-YES", "NO-NO", as described in Figure 3).

\subsubsection{Determinants of the Willingness to Pay}

In our study, we assessed the WTP for urban heat mitigation measures in Singapore. Furthermore, we explored how the UHI intensity in Singapore's different regions, how demographic and socio-economic factors, the level of awareness of the necessity for UHI mitigation measures, the level of attitudes towards mitigation measures, and outdoor preferences shape Singaporeans' WTP for urban heat mitigation.

Environmental awareness is defined as "knowledge about environmental problems and possible solutions to those problems" [57]. Previous studies have shown that people with rich environmental 
awareness are more inclined to exhibit pro-environmental attitudes, while a lack of environmental awareness limits people's pro-environmental attitudes [58-61]. In Canada, [61] found that 60\% of their respondents felt that their environmental attitudes were often limited by a lack of relevant awareness of environmental effects as well as on potential mitigation strategies. People with rich environmental awareness may also have a high level of awareness of UHI effects, its causes and its consequences, and exhibit positive attitudes towards UHI mitigation. Recent studies conducted in Beijing, China found that residents' level of awareness of UHI effect is positively and significantly related to their willingness to pay for green roofs and cool roofs, which are considered effective UHI mitigation strategies [32,33]. These studies suggest that timely information disclosure regarding urban environmental management (e.g., mitigation strategies and implementation by the government) and pro-environmental education might be helpful to get public support for the alleviation of UHI effects.

In our study, the level of awareness of the need for UHI mitigation was measured by the responses to the statements "The changing climate in Singapore is an urgent problem" and "Mitigation action needs to be taken for Singapore's changing climate." The responses were given on a 7-point Likert scale ranging from strong disagreement to strong agreement, which was then classified into three ordered categories of awareness: low, middle, and high. Responses indicating "strong disagreement" or "disagreement" with the above statements were classified as "low" awareness for UHI. Responses between "slight disagreement" and "slight agreement" were classified as "medium" awareness and responses of "agreement" and "strong agreement" were classified as "high" awareness.

The attitudes towards UHI mitigation were measured by using the responses to the statements "Improving the thermal comfort of outdoor spaces in Singapore is generally useful" and "It is important to ensure that something is done to make outdoor spaces thermally comfortable for outdoor activities in Singapore." The responses were made on a 7-point Likert scale, ranging from "strongly disagree" to "strongly agree," which were then classified into three ordered categories of attitudes towards UHI mitigation: negative, neutral, and positive. Responses that "strongly disagreed" or "disagreed" with the above statements were classified as "negative" attitudes, while responses between "slightly disagree" and "slightly agree" were classified as "neutral" attitudes. Responses of "agree" and "strongly agree" were classified as "positive" attitudes.

With respect to lifestyles, we were interested in the preferences for outdoor activities. Respondents' preferences towards spending time outdoors was measured with a 6-item scale (e.g., it is pleasant to spend time outdoors in Singapore) on a 7-point Likert scale with responses ranging from "strongly disagree" to "strongly agree." For a holistic measurement, 3 items focused on spending time outdoors during the day and 3 items focused on spending time outdoors at night. The aggregated responses were then classified into three ordered categories of outdoor preferences: preference to be indoors, neutral preference, and preference to be outdoors. Responses that "strongly disagreed" or "disagreed" with the statements mentioned above were classified as "negative" outdoor attitudes, while responses between "slightly disagree" and "slightly agree" were classified as "neutral" attitudes. Responses of "agree" and "strongly agree" were classified as "positive" outdoor attitudes.

\section{The Theoretical Model: Double-Bounded Dichotomous Contingent Valuation (DBDCV)}

As described above (Section 2.2.2), we received two binary answers from each individual $i(\mathrm{i}=1$, $\ldots, N$ ): whether he/she (1) accepts the first bid (YES or NO) and (2) accepts the second bid (YES or NO). If the initial bid is rejected, a lower bid is presented; otherwise a higher bid will be proposed. Hence, there are four possible outcome combinations in the respective decision tree: "YES-YES," "NO-NO," YES-NO," and "NO-YES."

Following [62], let us call the first bid amount $t_{i}^{1}$ and the second one $t_{i}^{2}$ for each respondent $i$. Then, each of the participants will be in one of the following categories:

1. If a subject answers YES to the first question and NO to the second question, we can infer that $t_{i}^{1}$ $\leq \mathrm{WTP}<t_{i}^{2}$.

2. If a subject answers YES to the first question and YES to the second, then $t_{i}^{2} \leq \mathrm{WTP}<\infty$. 
3. If a subject answers NO to the first question and YES to the second, then $t_{i}^{2} \leq \mathrm{WTP}<t_{i}^{1}$.

4. If a subject answers NO to the first and to the second question, then we have $0<\mathrm{WTP}<t_{i}^{2}$.

Now, let us define $D_{i}^{1}$ and $D_{i}^{2}$ as dichotomous variables that capture the YES-NO responses (i.e., YES is equal to 1 , otherwise 0 ) to the first question $\left(D_{i}^{1}\right)$ and to the second question $\left(D_{i}^{2}\right)$ for a respondent $i$. The probability that an individual's answers, for example, YES to the first question and NO to the second can then be expressed as:

$$
\operatorname{Pr}\left(D_{i}^{1}=1, D_{i}^{2}=0 \mid z_{i}\right)=\operatorname{Pr}(Y E S, N O)
$$

where $z_{i}$ is a vector of explanatory variables, such as demographic or socio-economic characteristics, etc. In order to simplify the notation, the right-hand side of the expression omits the fact that the probability is conditional on the values of the explanatory variables. Let us further assume that it is possible to estimate the WTP of a respondent $i$ based on the following linear model $[63,64]$ :

$$
\operatorname{WTP}_{i}\left(z_{i}, u_{i}\right)=z_{i}^{\prime} \beta+u_{i}
$$

where $\beta$ is a vector of parameters; $z_{i}^{\prime}$ is a vector with the values of the explanatory variables and $u$ as error term. The error term is assumed to follow a normal distribution: $u_{i} \sim N\left(0, \sigma^{2}\right)$ [64].

Given these assumptions, we have that the probability of each one of the four possible outcomes is given by:

1. $D_{i}^{1}=1$ and $D_{i}^{2}=1$

$$
\operatorname{Pr}(Y E S, Y E S)=\operatorname{Pr}\left(t^{1}<W T P \geq t^{2}\right)=\operatorname{Pr}\left(z_{i}^{\prime} \beta+u_{i}>t^{1}, z_{i}^{\prime} \beta+u_{i} \geq t^{2}\right)
$$

Using the Bayes rule, which says that $\operatorname{Pr}(\mathrm{A}, \mathrm{B})=\operatorname{Pr}(\mathrm{A} \mid \mathrm{B}){ }^{*} \operatorname{Pr}(\mathrm{B})$, we have:

$$
\operatorname{Pr}(Y E S, Y E S)=\operatorname{Pr}\left(z_{i}^{\prime} \beta+u_{i} \geq t^{1} \mid z_{i}^{\prime} \beta+u_{i} \geq t^{2}\right) * \operatorname{Pr}\left(z_{i}^{\prime} \beta+u_{i} \geq t^{2}\right)
$$

Here by definition $t^{2}>t^{1}$ and then: $\operatorname{Pr}\left(z_{i}^{\prime} \beta+u_{i} \geq t^{1} \mid z_{i}^{\prime} \beta+u_{i} \geq t^{2}\right)=1$, which implies:

$$
\operatorname{Pr}(Y E S, Y E S)=\operatorname{Pr}\left(u_{i} \geq t^{2}-z_{i}^{\prime} \beta\right)
$$

As we assume that $u_{i} \sim N\left(0, \sigma^{2}\right)$, we have that:

$$
\operatorname{Pr}(Y E S, Y E S)=\operatorname{Pr}\left(v_{i} \geq t^{2}-z_{i}^{\prime} \beta\right)=1-\Phi\left(\frac{t^{2}-z_{i}^{\prime} \beta}{\sigma}\right)
$$

where $v_{i} \sim N(0,1)$ and $\Phi(x)$ is the standard cumulative normal distribution. Therefore, by symmetry of the normal distribution, we have:

$$
\operatorname{Pr}(Y E S, Y E S)=\Phi\left(z_{i}^{\prime} \frac{\beta}{\sigma}-\frac{t^{2}}{\sigma}\right)
$$

2. $D_{i}^{1}=1$ and $D_{i}^{2}=0$

$$
\operatorname{Pr}(Y E S, N O)=\operatorname{Pr}\left(t^{1} \leq W T P<t^{2}\right)=\operatorname{Pr}\left(\frac{t^{1}-z_{i}^{\prime} \beta}{\sigma} \leq \frac{u_{i}}{\sigma}<\frac{t^{2}-z_{i}^{\prime} \beta}{\sigma}\right)=\Phi\left(\frac{t^{1}-z_{i}^{\prime} \beta}{\sigma}\right)-\Phi\left(\frac{t^{2}-z_{i}^{\prime} \beta}{\sigma}\right)
$$


where the last expression follows from $\operatorname{Pr}(a \leq X<b)=F(b)-F(a)$ and where $\mathrm{F}($.$) represents$ the cumulative distribution function. Therefore, using symmetry of the normal distribution we have that:

$$
\operatorname{Pr}(Y E S, N O)=\Phi\left(z_{i}^{\prime} \frac{\beta}{\sigma}-\frac{t^{1}}{\sigma}\right)-\Phi\left(z_{i}^{\prime} \frac{\beta}{\sigma}-\frac{t^{2}}{\sigma}\right)
$$

3. $D_{i}^{1}=0$ and $D_{i}^{2}=1$

$$
\begin{gathered}
\operatorname{Pr}(\text { NO, YES })=\operatorname{Pr}\left(t^{2} \leq W T P<t^{1}\right)=\operatorname{Pr}\left(\frac{t^{2}-z_{i}^{\prime} \beta}{\sigma} \leq \frac{u_{i}}{\sigma}<\frac{t^{1}-z_{i}^{\prime} \beta}{\sigma}\right)=\Phi\left(\frac{t^{2}-z_{i}^{\prime} \beta}{\sigma}\right)-\Phi\left(\frac{t^{1}-z_{i}^{\prime} \beta}{\sigma}\right) \\
\operatorname{Pr}(N O, Y E S)=\Phi\left(z_{i}^{\prime} \frac{\beta}{\sigma}-\frac{t^{2}}{\sigma}\right)-\Phi\left(z_{i}^{\prime} \frac{\beta}{\sigma}-\frac{t^{1}}{\sigma}\right)
\end{gathered}
$$

4. $D_{i}^{1}=0$ and $D_{i}^{2}=0$

$$
\begin{gathered}
\operatorname{Pr}(N O, N O)=\operatorname{Pr}\left(t^{2}>W T P<t^{1}\right)=\operatorname{Pr}\left(z_{i}^{\prime} \beta+u_{i}<t^{2}\right)=\Phi\left(\frac{t^{2}-z_{i}^{\prime} \beta}{\sigma}\right) \\
\operatorname{Pr}(N O, N O)=1-\Phi\left(z_{i}^{\prime} \frac{\beta}{\sigma}-\frac{t^{2}}{\sigma}\right)
\end{gathered}
$$

In order to proceed with the estimation, we construct a likelihood function with Equation (3) to (6) to obtain estimates for $\beta$ and $\sigma$ using a maximum likelihood estimation. In practice, it is convenient to work with the natural logarithm of the maximum likelihood function, called log-likelihood. Therefore, the function that needs to be maximized in order to find the parameters of the model is:

$$
\begin{aligned}
\ln L= & \sum_{i=1}^{N}\left[R_{i}^{Y Y} \ln \left(\Phi\left(z_{i}^{\prime} \frac{\beta}{\sigma}-\frac{t^{2}}{\sigma}\right)\right)+R_{i}^{Y N} \ln \left(\Phi\left(z_{i}^{\prime} \frac{\beta}{\sigma}-\frac{t^{1}}{\sigma}\right)-\Phi\left(z_{i}^{\prime} \frac{\beta}{\sigma}-\frac{t^{2}}{\sigma}\right)\right)\right. \\
+ & \left.R_{i}^{N Y} \ln \left(\Phi\left(z_{i}^{\prime} \frac{\beta}{\sigma}-\frac{t^{2}}{\sigma}\right)-\Phi\left(z_{i}^{\prime} \frac{\beta}{\sigma}-\frac{t^{1}}{\sigma}\right)\right)+R_{i}^{N N} \ln \left(1-\Phi\left(z_{i}^{\prime} \frac{\beta}{\sigma}-\frac{t^{2}}{\sigma}\right)\right)\right]
\end{aligned}
$$

where $R_{i}^{Y Y} ; R_{i}^{N N} ; R_{i}^{Y N} ; R_{i}^{N Y}$ are binary variables indicating the answers of each individual $i$ :

$R_{i}^{Y Y}$ (if the responses of $i$ th person are 'yes-yes' $=1 ; 0$ otherwise)

$R_{i}^{Y N}$ (if the responses of $i$ th person are 'yes-no' $=1 ; 0$ otherwise)

$R_{i}^{N Y}$ (if the responses of $i$ th person are 'no-yes' $=1 ; 0$ otherwise)

$R_{i}^{N N}$ (if the responses of $i$ th person are 'no-no' $=1 ; 0$ otherwise)

The variables $R_{i}^{Y Y} ; R_{i}^{N N} ; R_{i}^{Y N} ; R_{i}^{N Y}$ take the values of one or zero depending on the relevant responses for each individual. Equation (7) shows that a given individual contributes to the logarithm of the likelihood function in only one of its four parts. This approach allows us the direct estimation of $\beta$ and $\sigma$ using the maximum likelihood method. The estimation of the WTP will depend also on the values that we have for the vector $z_{i}^{\prime}$ (i.e., the values of the explanatory variables are described in Section 2.2.3).

\section{Results}

\subsection{Descriptive Statistics}

Table 3 displays the distribution of our survey participants over the seven bid combinations. The number and percentage of "YES-YES" responses fall sharply as the bids increase in value. This is accompanied by a rapid increase in the proportion of "NO-NO" responses. For example, for bid bundle 1 (i.e., 0.10/0.30/0.05, following Table 2), the proportion of "YES-YES" responses accounted for $21.21 \%$, while in bid bundle 7 (i.e., $4.50 / 5.50 / 3.00$ ) the percentage dropped significantly to $10.64 \%$ 
$(p=0.002)$. At the same time, the "NO-NO" responses rose significantly from $9.66 \%$ to $18.24 \%(p=$ 0.000). Overall, the "NO-NO" responses in this study accounted for $51.78 \%$ of the total sample size.

Table 3. Distribution of responses to the seven bid groups.

\begin{tabular}{cccccccccc}
\hline Bid Bundle & Sample & \multicolumn{2}{c}{ YES-YES } & \multicolumn{2}{c}{ YES-NO } & \multicolumn{2}{c}{ NO-YES } & \multicolumn{2}{c}{ NO-NO } \\
\hline Number & Observations & Freq. & $\mathbf{\%}$ & Freq. & $\mathbf{\%}$ & Freq. & $\%$ & Freq. & $\%$ \\
\hline 1 & 262 & 92 & 21.51 & 60 & 17.51 & 19 & 16.67 & 91 & 9.66 \\
2 & 261 & 79 & 18.44 & 54 & 15.73 & 27 & 24.07 & 101 & 10.84 \\
3 & 261 & 58 & 13.48 & 52 & 15.13 & 14 & 12.04 & 137 & 14.7 \\
4 & 262 & 56 & 13 & 51 & 14.84 & 16 & 13.89 & 139 & 14.81 \\
5 & 259 & 51 & 11.82 & 50 & 14.54 & 17 & 14.81 & 141 & 15.13 \\
6 & 260 & 48 & 11.11 & 43 & 12.46 & 14 & 12.04 & 155 & 16.63 \\
7 & 257 & 46 & 10.64 & 33 & 9.79 & 8 & 6.48 & 170 & 18.24 \\
\hline Total & 1822 & 430 & 23.5 & 343 & 18.72 & 115 & 6 & 934 & 51.78 \\
\hline
\end{tabular}

Table 4 displays the descriptive statistics of the demographic and socio-economic characteristics of our sample. Our sample was representative of the Singaporean and permanent resident population in terms of age, income, and gender, with the only exception of the older adults than are under-represented in our sample. The average annual income of our respondents was SGD \$57,790.34 (USD \$41,855.79), while the average annual income of the Singaporeans and permanent residents was SGD \$53,244 (USD $\$ 38,563.01)$.

In relation to the rest of the demographic characteristics, our sample was more educated than the general population, with $54.61 \%$ having a university education, attaining at least a Bachelor's degree (compared to $46.70 \%$ in the population). $75.08 \%$ of our sample was currently employed (compared to $67.70 \%$ in the population). $59.71 \%$ of our sample was married (compared to $60.20 \%$ in the population) and $45.77 \%$ had at least one child.

Figure 4 shows the descriptive statistics of the participants' awareness of need for UHI mitigation measures, their attitudes towards UHI mitigation, and their outdoor preferences. Slightly more than half of our respondents (53.26\%) were highly aware of the need for UHI mitigation measures in Singapore. $42.68 \%$ showed a middle level of awareness, while $4.06 \%$ had a low level of awareness. $63.69 \%$ of the persons in our sample expressed positive attitudes towards implementing UHI mitigation measures and hence making outdoor spaces thermally comfortable. $34.17 \%$ of the people in the sample declared to be neutral, while $2.14 \%$ indicated negative attitudes towards UHI mitigation. We observe that $64.51 \%$ of our sample preferred to spend time outdoors. $29.3 \%$ of the sample were neutral or had no particular preference for indoors versus outdoors activities, while $5.76 \%$ preferred to be indoors. 
Table 4. Descriptive statistics of sample. Demographic and socioeconomic variables.

\begin{tabular}{|c|c|c|}
\hline $\begin{array}{c}\text { Demographic and Socio-Economic } \\
\text { Characteristics }\end{array}$ & Number of Respondents & Percentage of Respondents (in \%) \\
\hline Gender & Males: 910: Female 899 & males 49.92: Females 49.29 \\
\hline \multicolumn{3}{|c|}{ Age distribution } \\
\hline 20 to 29 & 389 & 21.34 \\
\hline 30 to 39 & 481 & 26.39 \\
\hline 40 to 49 & 435 & 23.86 \\
\hline 50 to 59 & 391 & 21.45 \\
\hline 60 and above & 127 & 6.97 \\
\hline \multicolumn{3}{|c|}{ Gross monthly income } \\
\hline No Income & 43 & 2.36 \\
\hline less_than_\$1000 & 61 & 3.35 \\
\hline$\$ 1001-\$ 2000$ & 96 & 5.27 \\
\hline$\$ 2001-\$ 3000$ & 108 & 5.93 \\
\hline$\$ 3001-\$ 4000$ & 106 & 5.82 \\
\hline$\$ 4001-\$ 5000$ & 114 & 6.26 \\
\hline$\$ 5001-\$ 6000$ & 139 & 7.63 \\
\hline$\$ 6001-\$ 7000$ & 116 & 6.37 \\
\hline$\$ 7001-\$ 8000$ & 100 & 5.49 \\
\hline$\$ 8001-\$ 9000$ & 87 & 4.77 \\
\hline$\$ 9001-\$ 10,000$ & 78 & 4.28 \\
\hline$\$ 10,001-\$ 11,000$ & 109 & 5.98 \\
\hline$\$ 11,001-\$ 12,000$ & 51 & 2.8 \\
\hline$\$ 12,001-\$ 13,000$ & 90 & 4.94 \\
\hline$\$ 13001-\$ 14000$ & 48 & 2.63 \\
\hline above_\$14,000 & 476 & 26.12 \\
\hline \multicolumn{3}{|l|}{ Education } \\
\hline Primary \& below & 27 & 1.48 \\
\hline n/o levels & 209 & 11.47 \\
\hline A levels/diploma & 564 & 30.96 \\
\hline bachelors & 769 & 42.21 \\
\hline postgraduate & 226 & 12.4 \\
\hline \multicolumn{3}{|l|}{ Employment } \\
\hline student & 58 & 3.18 \\
\hline employed & 1,368 & 75.08 \\
\hline self-employed & 145 & 7.96 \\
\hline unemployed(seeking) & 184 & 10.1 \\
\hline \multicolumn{3}{|l|}{ Number of Children } \\
\hline 0 & 988 & 54.23 \\
\hline 1 & 414 & 22.72 \\
\hline 2 & 311 & 17.07 \\
\hline 3 or more & 100 & 5.69 \\
\hline \multicolumn{3}{|l|}{ Marital Status } \\
\hline single & 637 & 34.96 \\
\hline married & 1,088 & 59.71 \\
\hline divorced/separated & 81 & 4.45 \\
\hline
\end{tabular}

Note: 13 respondents preferred not to declare their gender; 27 did not declare their education level, 67 their employment status, 16 their marital status, and 9 the number of children in their household. 


\section{Outdoor Preferences}

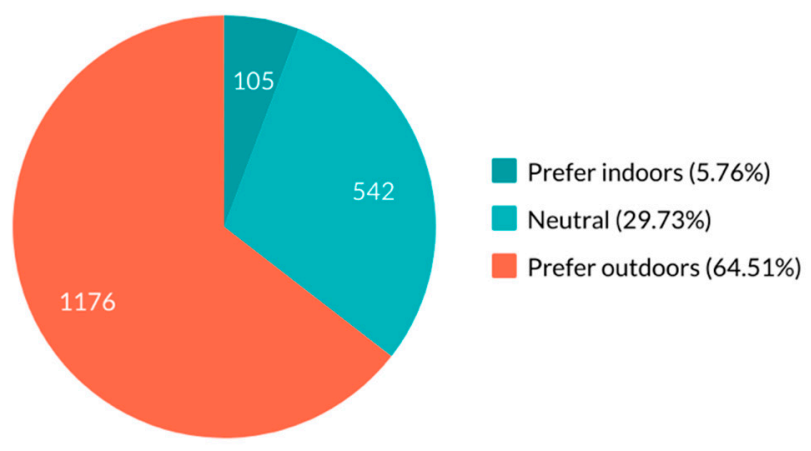

\section{Awareness of Need for UHI Mitigation Attitudes Towards UHI Mitigation}

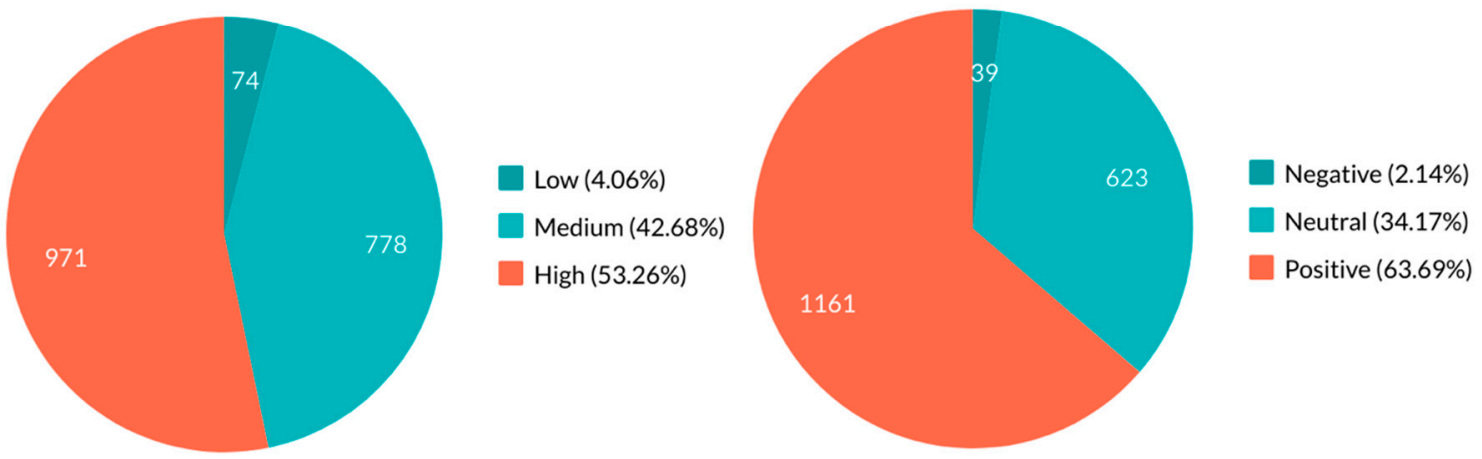

Figure 4. Descriptive statistics from our sample on the level of awareness of the need for UHI mitigation measures, on attitudes towards UHI mitigation as well as on outdoor preferences.

\subsection{UHI Assessment and WTP Estimation}

\subsubsection{UHI Assessment}

In this subsection, we apply the methodology described in Section 2.1. to assess the UHI intensity in Singapore. Following [24] the UHI intensity is defined as the difference between the $2 \mathrm{~m}$ air temperature in the urban and in the all-green scenario. As mentioned earlier, we sorted our sample according to the postal code of the participants into five Singaporean regions: Central Region, Northeast Region, North Region, West Region, and East Region. This division of the territory is also used for urban planning by the Urban Redevelopment Authority of Singapore. Over time, other governmental organizations have also adopted the five regions in their administrative work, for example, the Department of Statistics in the national census.

Figure 5 presents a map of Singapore which shows the UHI intensity for the five Singaporean regions. The UHI intensities were averaged for each of the regions. As stated in Section 2.1, we excluded any non-residential areas from the analysis (i.e., urban parks and industrial areas). The resulting average UHI intensities are $2.2{ }^{\circ} \mathrm{C}$ in the Central Region; $1.6^{\circ} \mathrm{C}$ in the North and Northeast Region and $2.08^{\circ} \mathrm{C}$ in the West Region. This means that the Central Region presents the highest UHI intensity followed by the West Region (see Figure 5). 
The diurnal cycle of the ensemble (i.e., average of $2 \mathrm{~m}$ air temperature over $24 \mathrm{~h}$ for April 2016) UHI intensity (averaged per LCZ type) for each of the regions is shown in Figure 6. During most of the night (i.e., from 21:00 LT to 04:00 LT), the UHI intensities are smooth and stay at their daily peaks for all the LCZs. UHI intensities for all urban areas decrease quickly from 07:00 LT to noon. No negative UHI intensity was observed in all LCZs in the Central Region. The negative UHI refers to a Cool Island which means that there will be some spots having cooling effect at noon.

Most LCZs except for sparsely built areas (LCZ 9) in North and Northeast Regions showed signs of negative UHI while in the East Region negative UHI was observed in compact high rise (LCZ 1) in addition to LCZ 9.

Figure 6 shows that the night-time UHI intensity was much higher than the day-time intensity, with a maximum of $4.2^{\circ} \mathrm{C}$ for the difference between night and day. The fact that our maximum UHI intensity is smaller than in the study of [24] is due to variations in the land use assumed. We were not contemplating industrial areas that generally presents a higher UHI. A further explanation is that we were moving from an island-wide estimation to a regional level. A decrease in the number of urban structures and elements results in a reduction of stored heat and therefore, less heat is released back into the environment during the night. Our UHI intensities estimations are higher than those reported by [65], possibly because April 2016 was a very hot period, with a record-setting maximum temperature of $36.4{ }^{\circ} \mathrm{C}$ (Meteorological Service Singapore, 2017). The difference between [65] and our analysis is also that they used a single layer urban canopy model, which is less descriptive of urban heterogeneity as compared to the multi-layer urban canopy model we used. [65] used prescribed anthropogenic heat profiles while in our case we focused on dynamic anthropogenic heat from the AC systems in the buildings. The UHI intensity from our study is within the range typically found for tropic countries $\left(\sim 4^{\circ} \mathrm{C}\right)$, as summarized in [66]. 


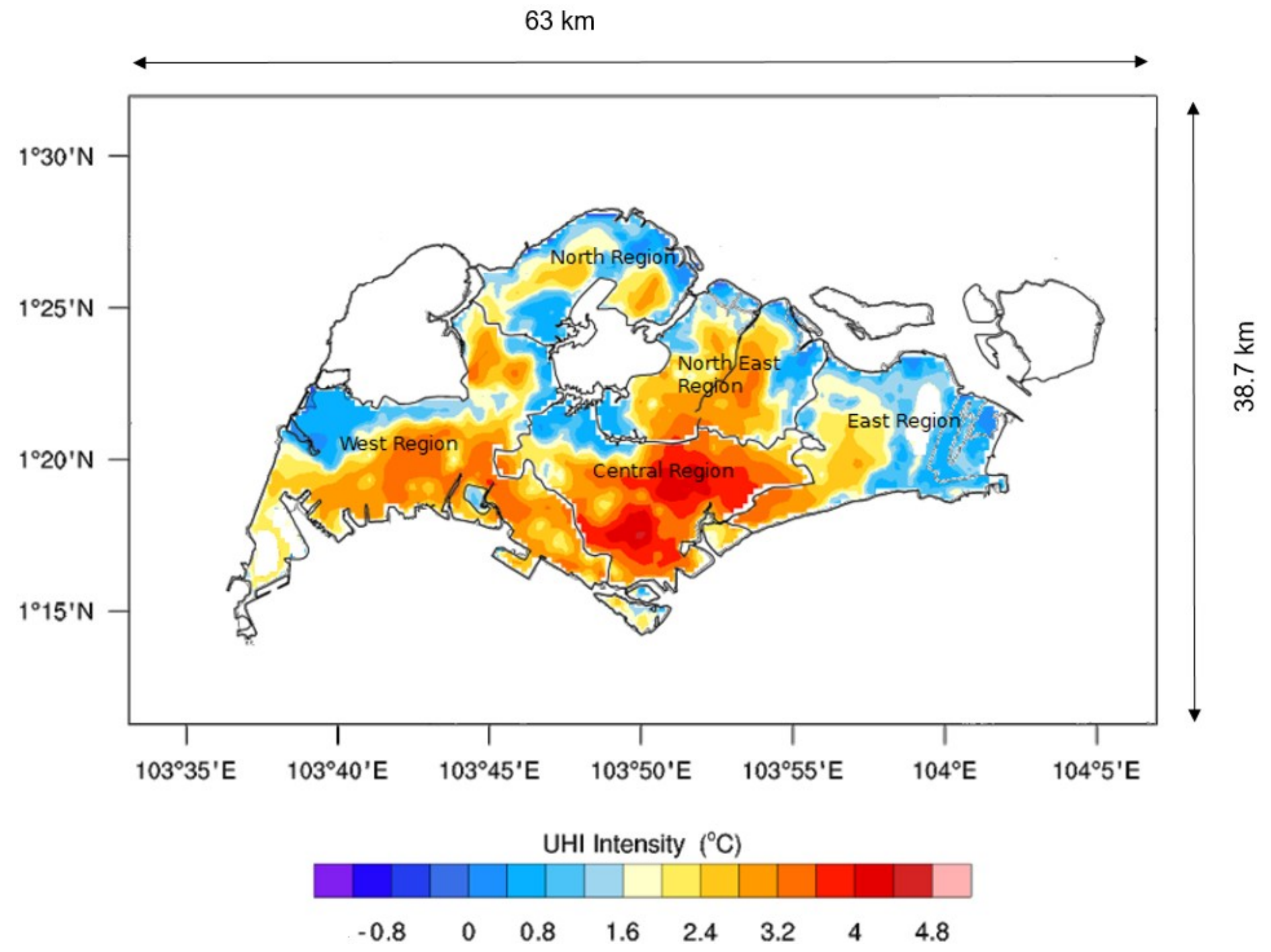

Figure 5. Spatial distribution of UHI intensities in Singapore. Data from April 2016 at 04:00 LT. 


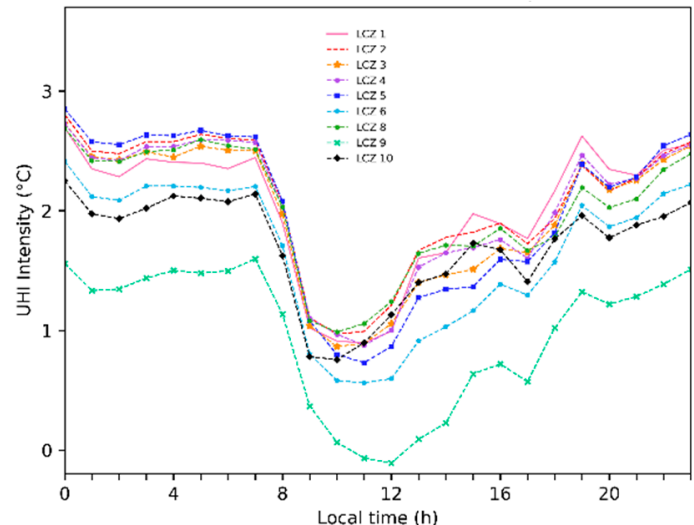

(a) Northeast Region

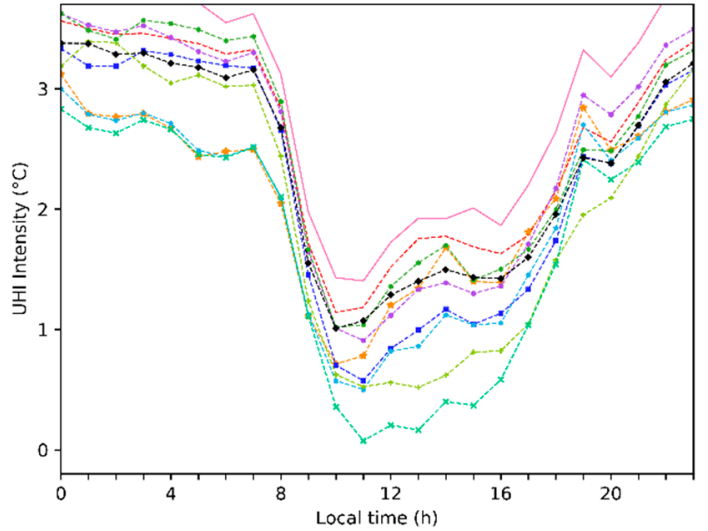

(c) Central Region

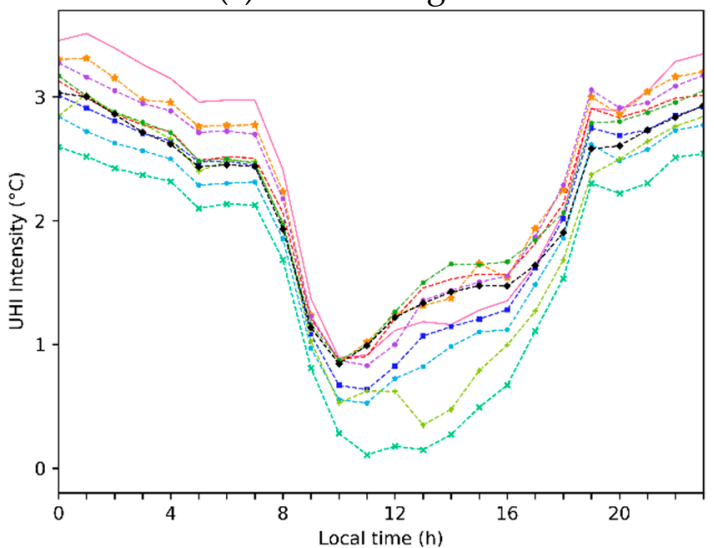

(e) West Region

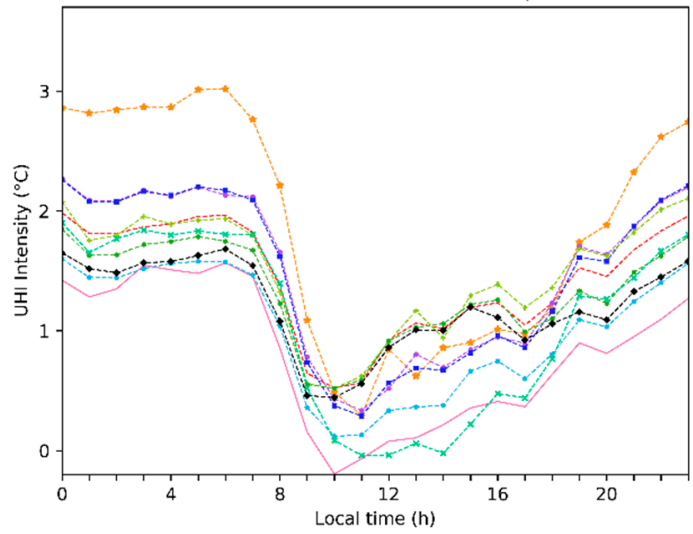

(b) East Region

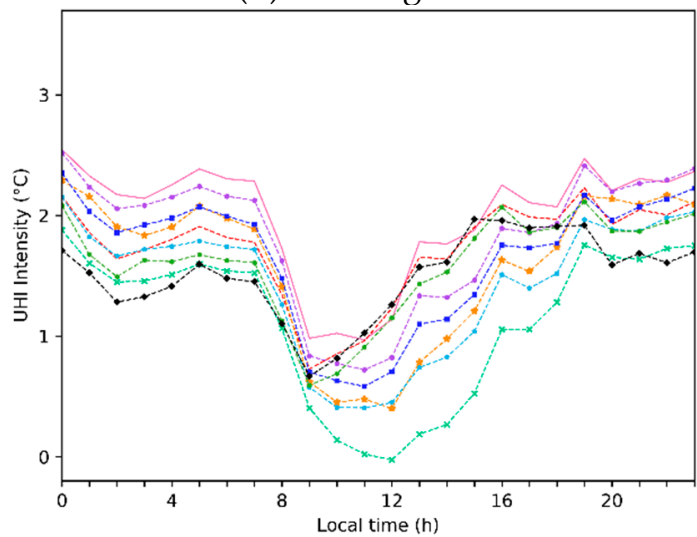

(d) North Region

Figure 6. Diurnal variation of the UHI intensity assessment for the (a)Northeast Region, (b)East Region, (c)Central Region, (d)North Region, and (e)West Region during April 2016.

\subsubsection{WTP Estimation Results}

After having analyzed and measured the mean UHI intensity level in the five regions of Singapore (Section 4.2.1), we estimated the WTP of the respondents living in each region using Equation (7). Table 5 shows the number of respondents living in each of the five regions, the respective estimated mean WTP, the mean UHI intensity, the mean annual income of the sample in each region, and the percentage of the mean annual income citizens are willing to pay in mean for UHI mitigation. The mean annual income was used in Table 5 for comparison purposes, given that the personal income tax was our payment "vehicle" in the WTP elicitation (see Section 2.2.1). Wilcoxon Mann-Whitney tests were performed to test for differences across the regions. 
Table 5. Mean WTP, UHI intensity, and mean annual personal income per region.

\begin{tabular}{|c|c|c|c|c|c|c|c|}
\hline (1) & (2) & (3) & (4) & (5) & (6) & (7) & (8) \\
\hline Regions & $\begin{array}{l}\text { Number of } \\
\text { Respondents } \\
\text { Per Region }\end{array}$ & $\begin{array}{c}\text { Estimated } \\
\text { Population } \\
\text { Per Region }{ }^{1}\end{array}$ & $\begin{array}{c}\text { \% of } \\
\text { Respondents } \\
\text { from the } \\
\text { Estimated } \\
\text { Population }\end{array}$ & $\begin{array}{l}\text { Mean WTP } \\
\text { Estimation } \\
\text { Per } \\
\text { Singaporean } \\
\text { (in SGD\$) }\end{array}$ & $\begin{array}{l}\text { Mean UHI } \\
\text { Intensity } \\
\text { (in }{ }^{\circ} \mathrm{C} \text { ) }\end{array}$ & $\begin{array}{c}\text { Mean } \\
\text { Annual } \\
\text { Income } \\
\text { (in SGD\$) }\end{array}$ & $\begin{array}{c}\text { \% WTP } \\
\text { from the } \\
\text { Mean } \\
\text { Annual } \\
\text { Income }\end{array}$ \\
\hline Central & 429 & 753,068 & 0.057 & 665.968 & 2.2 & $56,661.97$ & 1.18 \\
\hline East & 311 & 516,138 & 0.060 & $218.656 * * *$ & $1.31^{* * *}$ & $57,533.98$ & $0.38^{* * *}$ \\
\hline North & 245 & 404,038 & 0.061 & $138.748^{* * *}$ & $1.6^{* * *}$ & $57,719.01$ & $0.24^{* * *}$ \\
\hline Northeast & 439 & 752,028 & 0.058 & $84.232 * * *$ & $1.6^{* * *}$ & $56,471.4$ & $0.15^{* * *}$ \\
\hline West & 398 & 751,428 & 0.053 & $120.292^{* * *}$ & $2.08^{* * *}$ & $60,969.7$ & $0.20 * * *$ \\
\hline Total & 1822 & $3,176,700$ & 0.29 & 246.51 & 1.758 & 57,790 & 0.43 \\
\hline
\end{tabular}

From Table 5, we observe that the Northeast and Central Regions have more respondents than other regions (439 and 429 out of our 1822 respondents). The North region has the lowest number of respondents in our sample. However, when we calculate the percentage of respondents from the estimated population in the respective areas (Column 4 in Table 5), we do not find any significant differences across the regions. This means that the number of our respondents in each of the regions is proportionally distributed across them.

Column 5 in Table 5 shows the mean WTP estimations per region. The mean WTP estimated for the respondents in the Central region is significantly higher than the one in the Northeast Region $(p=0.000)$, East Region $(p=0.000)$, North Region $(p=0.000)$, and West Region $(p=0.000)$. The Central Region represents the highest WTP, while the Northeast Region shows the lowest WTP of all five regions. The East Region has the second highest mean WTP with SIN $\$ 218,66$, followed by the North and West Region, respectively.

Column 6 in Table 5 displays the mean UHI intensity across the regions. The mean UHI intensity is the highest in the Central Region and this difference is significant when compared with the East Region $(p=0.000)$, North Region $(p=0.000)$, Northeast Region $(p=0.000)$, and West Region $(p=0.000)$.

In Column 7 of Table 5, we show the mean annual incomes per region and in Column 8, we display per region the residents' WTP as a percentage of the mean annual income. Respondents in the Central Region are willing to pay $1.18 \%$ of their annual income on UHI mitigation. Respondents in the East Region, North Region, Northeast Region, and West Region are willing to pay in mean a significantly lower proportion of their mean annual income than respondents living in the Central Region ( $p=0.000$ for all respective comparisons).

\subsubsection{Determinants of the WTP Estimation}

In this subsection, we want to explore the determinants of the WTP estimation. We used Equation (7) to do a log-likelihood estimation of the WTP with and without the set $\mathrm{z}$ of explanatory variables. In the set $\mathrm{z}$ of explanatory variables, we included the UHI intensity level per region as well as the individuals' characteristics. Willingness-to-pay estimation was performed using STATA [62]. Table 6 shows the estimation results. Column 1 indicates the results of our model without the full set of explanatory variables. The only included "explanatory" variable is the "bid" variable representing the value of the different bids. In Column 2, we added to the "bid" variable the "mean UHI intensity per region" as a covariate. Column 3 presents the regression results with the "bid" variable, "mean UHI intensity per region," and in addition, our set of demographic and socio-economic variables. Lastly, Column 4 presents the regression results with the same covariates as in Column 3, but with the further addition of the "level of awareness of need for UHI mitigation measures," the "level of attitudes towards UHI mitigation," and the "outdoor preferences" covariates. The aim of this 
analysis progressing from Column 1 to Column 4 is to assess whether the additional variables that are considered from column to column provide additional explanatory power to the WTP estimation.

Table 6. Estimation results of the log- likelihood of a "YES" response to the bid.

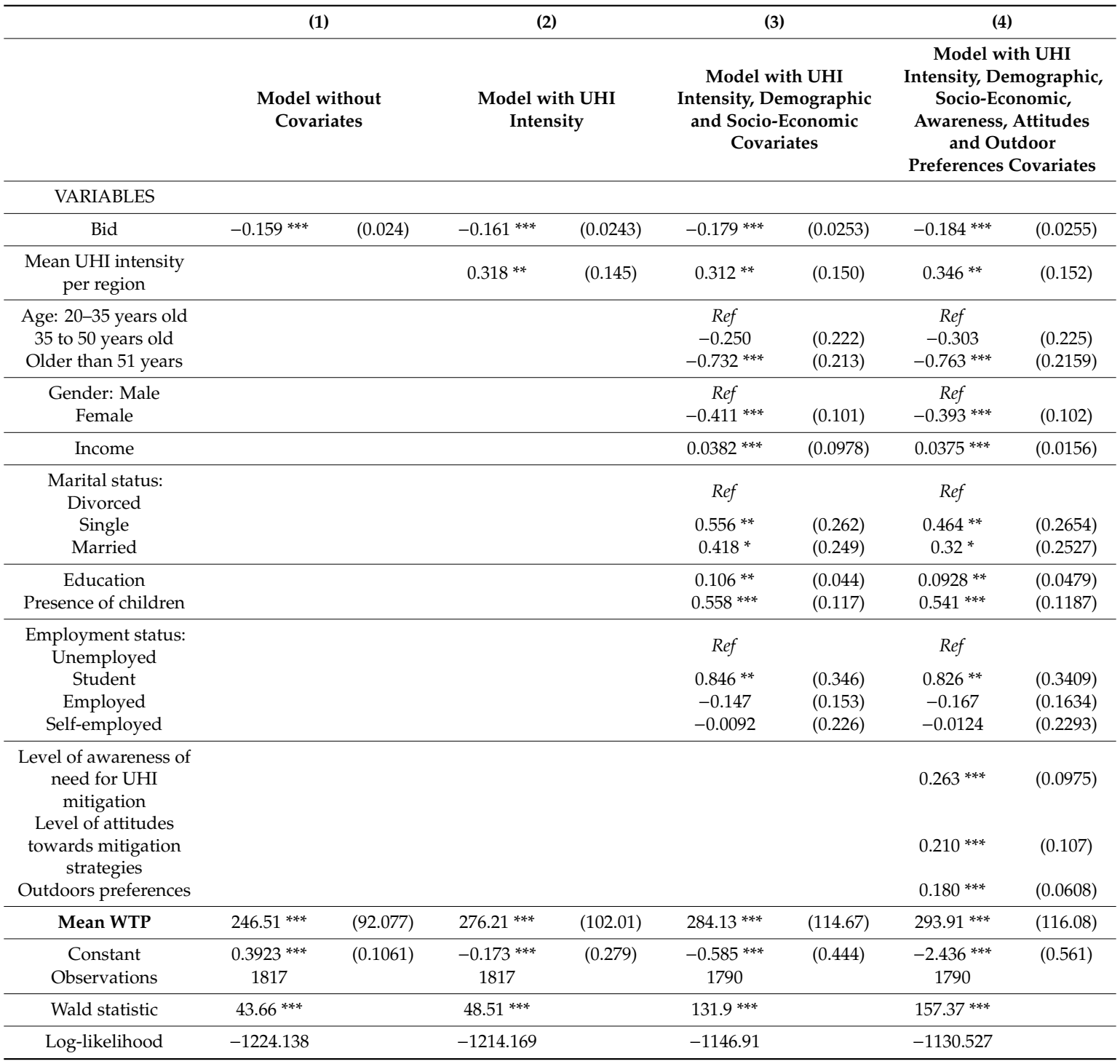

Notes: Standard errors in parentheses ${ }^{* *} p<0.01,{ }^{* *} p<0.05,{ }^{*} p<0.1$. Mean WTP in SGD\$.

In Column 1 from Table 6, the coefficients of the "bid" are negative and statistically significant, which implies that the likelihood of a "YES" response decreases as the value of the bid increases. This result is consistent with the results observed in Columns 2, 3, and 4.

Column 2 of Table 6 displays the estimation results including the average UHI intensity per region displayed in Table 5. We observe that the coefficient for the new variable is positive and significant, consistently with the result observed in Columns 3 and 4, suggesting that the mean UHI intensity has a positive impact on the likelihood of saying "YES" to the bid. Since the model in Column 1 is nested in the model underlying Column 2, we can perform a likelihood ratio test. The likelihood ratio test involves estimating two models and comparing them. Specifically, this test is used to compare the log-likelihoods of the two models and it tests whether a difference is statistically significant. If the difference is statistically significant, then the less restrictive model (i.e., the one with more variables) is said to fit the data significantly better than the more restrictive model. The log-likelihood of our models are displayed at the bottom of Table 6 . The test statistic of the likelihood ratio test comparing Column 1 and Column 2 of Table 6 is 4.87 and the associated p-value is significant $(p=0.0273)$. This result shows 
that adding "Mean UHI intensity per region" as a predictor variable results in a statistically significant improvement in the model fit.

In Column 3 of Table 6, we further introduced demographic and socio-economic variables, i.e., gender, age and (declared) annual income, education, presence of children in the household, marital, and employment status. Before doing so, we tested for correlation across these characteristics to avoid any potential multicollinearity in our estimations. Our results suggested that there were no high correlations across the demographic and socio-economic variables inserted in the model of Column 3. We see from Column 3 that females tend to respond "YES" $41.10 \%$ less often than men and that difference is statistically significant. The coefficient of the variable "Income" is positive and significant, which suggests that the higher the income of the respondents, the higher is the probability of a positive response to a bid. In order to capture the probability of positive responses with respect to age, we split our sample into three age groups "20 to 35 years old" (our benchmark), "35 to 50 years old" and "older than 51 years old." We observe that respondents "older than 51 years" tended to respond "YES" to the bid significantly less often than respondents from "20 to 35 years old" and also significantly less than the respondents between " 35 to 50 years old" (coef. $=-0.481 ; p=0.000$ ).

We also evaluated in Column 3 of Table 6 the role of the participants' marital status: the coefficients of the variables "single" and "married" are positive and significant compared to divorced participants. However, there is no significant difference in saying "YES" to the bid between "single" and "married" (coef. $=-0.137 ; p=0.301$ ).

Furthermore, we evaluated the contribution of the respondents' employment situation to the probability of a "YES" response to the bid. We found the probability to be significantly higher for students than for unemployed respondents (benchmark), but also higher for students than for self-employed (coef. $=0.95 ; p=0.050$ ) and employed respondents (coef. $=1.13 ; p=0.000$ ). The level of education of the respondents seems to play a significant role in eliciting positive responses to bids. The significant influence of education on WTP has also been found in a previous study on the WTP for UHI mitigations in Asia [32,33]. The variable "presence of children" is a binary variable which takes the value "one" when the respondents have children living in their household and which is zero otherwise. We observe that the coefficient of the variable "presence of children" is positive and significant, which suggests that people with children were more likely to give a positive response to the bid than those without children.

We also performed the likelihood ratio test to see whether the additional demographic and socio-economic variables in Column 3 improved the fitness of the estimation compared with Column 2 , in which only the "bids" and "mean UHI intensity per region" were used as covariates. The test statistics is 15.32 and it is highly significant $(p=0.000)$, suggesting that the set of demographic and socio-economic characteristics increase significantly the fitness of the estimation.

In column 4 of Table 6, we further incorporated the "awareness of the need for UHI mitigation strategies," the "attitudes towards UHI mitigation strategies" as well as the "outdoor preferences" into our analysis. We tested for correlations across the variables prior to introducing them into the model to avoid any potential multicollinearity in our estimations. Correlation tests confirmed that there were no high correlations across the variables under evaluation (level of awareness vs. level of attitudes: Spearman's rho $=0.4502 ; p=0.000$; level of awareness vs. outdoor preferences: Spearman's rho $=0.1480 ; p=0.000$; level of attitudes vs. outdoor preferences: Spearman's rho $=0.1996 ; p=0.000$ ). We observe that the three coefficients for the "awareness of the need for UHI mitigation," "attitudes towards mitigation strategies" and "outdoor preferences" are positive and significant. This implies that the higher the level of awareness of the need for UHI mitigation measures, the more positive the attitudes are towards mitigation measures and the higher the preference is for spending time outdoors, the higher is the probability of saying "YES" to the bids. We again performed the likelihood ratio test to test whether the introduction of these three extra variables improved the model fit by comparing the estimations from Column 3 and Column 4 . The result gives a test statistic of 33.77 with a highly significant $\mathrm{p}$-value $(p=0.000)$. This means that, also in this case, the additional variables inserted in 
Column 4 capturing the level of awareness, the level of attitudes, and outdoor preferences increased the fit of the model.

Overall, it turns out that the estimated average WTP is SGD $\$ 246.51$ per Singaporean and per year (95\% CI [SGD \$66.04; SGD \$426.98]) in the estimation without covariates (Column 1). It increases to SGD \$276.21 per person and year (95\% CI [SGD \$53.67; SGD \$498.98]) when we introduce in the estimation the UHI intensity in the regions (Column 2). It raises to SGD $\$ 284.13$ per person and year (95\% CI [SGD\$ 59.37; SGD\$ 508.88]) in the estimation with UHI intensity per region and demographic and socio-economic characteristics (Column 3). The WTP increased further to SGD \$293.91 per person and year (95\% CI [SGD \$46.39; SGD \$501.43]) in the estimation with the further addition of the level of awareness, level of attitudes and outdoor preferences (Column 4).

For conservative reasons, we consider the total average WTP from the estimation without covariates displayed in Table 5 (i.e., SGD \$246.51). As reported previously, the average annual income of our sample is SGD $\$ 57,790.34$. This means that the total average WTP represents $0.43 \%$ of the average annual income of our respondents. and also represents the $0.41 \%$ of the Singapore GDP per capita at the moment of the survey (with a GDP per capita of SGD $\$ 60,297.79$ ).

Expanding the mean annual WTP value (i.e., SGD \$246.51) to the 3.18 million working adults in Singapore at the moment of the survey, Singaporeans would be willing to pay a total of SGD $\$ 783.08$ million (USD $\$ 563.82$ million) per year for promoting the implementation of UHI mitigation measures. The corresponding 95\% WTP interval would comprise SGD \$209.78 million (USD \$151.05 million) per year at the lower limit and SGD $\$ 1.04$ billion (USD \$47.87 million) per year at the upper limit.

In Table 5, we displayed the estimated mean WTP per Singaporean per region (Column 5). By expanding this WTP to the Singaporeans and permanent residents living in each of the regions (Table 5, Column 3), we calculated the total annual mean WTP per region. The total annual mean WTP for the Central Region represents the 63\%, while for the East Region, North Region, Northeast Region, and West Region represent the $13.37 \%, 6.10 \%, 7.03 \%$, and $10.49 \%$, respectively of the total annual mean WTP of SGD $\$ 783.08$ million estimated for Singapore as a whole.

\section{Discussion}

In this study, we sought to assess and understand the willingness to pay of Singapore citizens and permanent residents for measures to mitigate the UHI effect in Singapore. We found that the citizens were willing to contribute considerable amounts of their incomes towards implementing UHI mitigation measures in their country of residence. This finding is highly interesting as it is the first of its kind to show how much citizens value the UHI mitigation in Singapore [27].

The Singaporean government has indicated that fighting against climate change and its related risks and impacts is one of the main priorities for the country. In its government budget for 2020, Singapore also announced committing close to SGD $\$ 1$ billion for climate change mitigation and adaptation efforts [67]. In the context of our findings, we found that Singapore citizens are willing to pay SGD $\$ 783.08$ million (USD $\$ 563.82$ million) per year for implementing UHI mitigation strategies, which equates to about $78 \%$ of the budget committed by the government for climate change mitigation as a whole. It is interesting to see that our WTP estimate also corresponds to about $27 \%$ of Singapore's Ministry for Environment and Water Resources' SGD \$2.94 billion budget and to 7.68\% of Singapore's Ministry of Health's SGD $\$ 10.2$ billion budget for the fiscal year 2020 [67]. This underlines the strong support among citizens for tackling climate change challenge and its health-related issues faced by Singapore, of which UHI mitigation is an important part.

Apart from estimating the social benefits that could be derived from the implementation of UHI mitigation strategies, which are implicitly captured by the WTP, we also aimed to analyze the relationship between WTP estimates and UHI intensity through a spatial analysis. In terms of policymaking, it is important to know how much people are willing to pay to implement UHI mitigation measures in the different Singaporean regions, which present diverse UHI intensities. In our analysis, we found that the UHI exposure of the respondents was one of the key predictors of the WTP for UHI 
mitigation measures. The WTP of citizens who lived in the region with the highest UHI intensity was 3.09 times higher than of those living in the region with the lowest UHI intensity. In particular, we found the highest WTP among citizens living in the Central Region, which is also characterized by the highest mean UHI intensity. Citizens in the Central Region are willing to pay $63 \%$ of the total mean WTP of the entire Singapore. In the West region, however, where the mean UHI intensity is the second highest, citizens reported the second lowest WTP. Indeed, citizens in the West Region are willing to pay only $10.49 \%$ of the total annual WTP for the whole Singapore. This suggests that the exposure to UHI, even though significant, is only one of several predictors for the UHI mitigation related WTP.

Investigations into demographic, socioeconomic, and psychological predictors showed that the WTP differs across population groups, independently of the regions in which they live. Citizens who are younger, better educated, have a higher income and live together with children report higher WTP values. Men report higher WTP than women. These results are not surprising. [35] and [50] found that childless individuals are less willing to pay for environmental goods than parents. [35] found that men are willing to pay more than women for environmental programs. Besides, other studies suggest (e.g., [68,69]) that since seniors are less likely to live in the more distant future than younger people, they are less likely to profit from the implementation of environmental programs and are therefore willing to pay less than younger people for a given future risk reduction.

In addition, we found that citizens who reported awareness of the need for UHI mitigation measures, hold positive attitudes towards UHI mitigation and prefer outdoor settings in general report higher WTP values. To better protect older people as one of the most vulnerable groups from negative UHI effects and heat exposure, education might be useful and increase the overall WTP for UHI mitigation.

Our findings suggest that the level of support for UHI mitigation measures is homogeneous across Singapore. It differs according to the exposure to UHI, to income, gender, age, and parenthood status, as well as to the individual's awareness of its need and their attitudes towards UHI mitigation and outdoor preferences. It is thus important to consider these factors when designing UHI mitigation measures and the strategy for garnering public support for them. Considering that there is a sizeable difference between the WTP across the different population groups, policymakers need to be sensitive to these differences when considering if and how much to tax citizens for UHI mitigation.

While our findings have provided important first indications that the citizens and residents of Singapore support efforts to mitigate UHI in the country, the amount of SGD \$783.08 million only gives a conservative indication that there is a general support for the respective measures in the population. Next, it is important for policymakers, researchers, industry and also for citizens to choose specific mitigation measures which they would support. Currently, more than eighty mitigation measures are proposed for Singapore [27], each with varying levels of efficacy, costs, and benefits to citizens' lives. It is hence critical to identify the measures that are acceptable for most groups, so that the respective sizeable investments will get sustainable funding. This is even more important since for the next decades further urban development and hence higher UHI effects might be expected. Therefore, urban land planning and decision-making that contemplates the UHI effects, its intensity across the country and its impacts on the population are key to guarantee future liveability of Singapore.

\section{Conclusions and Implications}

In the face of the current UHI challenge in Singapore, we found that citizens and permanent residents show considerable support for mitigation measures. Our findings suggest that citizens are aware of the impacts of UHI and support mitigation measures to be financed by their taxes.

We conclude with the following recommendations for policymakers in Singapore and in cities facing similar challenges related to UHI effects.

1. Singapore citizens and permanent residents express a strong willingness to pay for mitigating the UHI effect in Singapore. This should encourage policymakers to further increase their efforts 
to address the UHI effect in Singapore and to continue improving the urban outdoor thermal environment, particularly in those areas with a high UHI intensity.

2. Stimulating education and awareness for issues related to environmental and urban sustainability might generate a higher public support for the implementation of UHI mitigating measures.

Finally, building on the findings and the process underlying this research, we suggest the following to be considered in future research.

1. Further CVM-related research on mitigating the UHI effect is recommended to provide further insights into the differences in WTP within the population. In particular, the relationship between WTP for specific UHI mitigation measures and the vulnerability of different population groups (for example older adults and young children) should be further explored.

2. As our study presented the mitigation measures as a bundle, we were not able to calculate the WTP for specific mitigation measures. Nevertheless, it is important to understand how much citizens are willing to pay for different mitigation measures. Based on such information, measures could be ranked and implemented according to their WTP. With respect to the implementation, the expected discounted costs for different UHI mitigation measures should also be taken into account. Combining this information within a cost-benefit analyses would provide policymakers with deeper insights which could guide their policy decisions.

Supplementary Materials: The following are available online at http://www.mdpi.com/2225-1154/8/7/82/s1, Survey Questionnaire S1.

Author Contributions: All the authors conceived and designed the study. N.B. and S.C. performed the implementation of the methodology and the analysis of the data. M.O.M. performed the UHI assessment for the spatial analysis. R.S. structured and revised the manuscript and supervised the project. All the authors contributed towards the interpretation of the results and the writing of the manuscript. All authors have read and agreed to the published version of the manuscript.

Funding: The research was mainly conducted under the Cooling Singapore project, funded by Singapore's National Research Foundation (NRF) under its Virtual Singapore programme. Cooling Singapore is a collaborative project led by the Singapore-ETH Centre (SEC), with the Singapore-MIT Alliance for Research and Technology (SMART), TUMCREATE (established by the Technical University of Munich), the National University of Singapore (NUS), the Singapore Management University (SMU), and the Agency for Science, Technology and Research (A*STAR). S.C is partially funded by the Chen Tianqiao Program for Urban Innovation at the Lee Kuan Yew Centre for Innovative Cities, Singapore University of Technology and Design. The views expressed are those of the authors and not necessarily those of the above funders.

Acknowledgments: The authors are thankful to Lea Ruefenacht, Ido Nevat and Rochelle Chua from the Cooling Singapore project for providing insights and expertise that assisted the research. The authors thank specially to Professor Gerhard Schmitt, Lead Principal Investigator of the Cooling Singapore project, for his valuable support. The authors would also like to thank the editors and two anonymous reviewers for their comments and suggestions to strengthen this manuscript. The authors would like to thank the Meteorological Service Singapore (MSS) for providing the climatic/meteorological data.

Conflicts of Interest: The authors declare no conflict of interest.

\section{References}

1. Mathew, A.; Khandelwal, S.; Kaul, N. Analysis of diurnal surface temperature variations for the assessment of surface urban heat island effect over Indian cities. Energy Build. 2018, 159, 271-295. [CrossRef]

2. Berdahl, P.; Bretz, S.E. Preliminary survey of the solar reflectance of cool roofing materials. Energy Build. 1997, 25, 149-158. [CrossRef]

3. Oke, T.R. Applied Climatology: Principles and Practice; Thompson, R.D., Perry, A., Eds.; Routledge: New York, NY, USA, 1997.

4. Sailor, D.J.; Dietsch, N. The urban heat island mitigation impact screening tool (MIST). Environ. Model. Softw. 2007, 22, 1529-1541. [CrossRef]

5. Costa, S.; Ferreira, J.; Silveira, C.; Costa, C.; Lopes, D.; Relvas, H.; Paulo Teixeira, J. Integrating health on air quality assessment-Review report on health risks of two major European outdoor air pollutants: PM and $\mathrm{NO}_{2}$. J. Toxicol. Environ. Health Part B 2014, 17, 307-340. [CrossRef] 
6. Godish, T.; Davis, W.T.; Fu, J.S. Air Quality; CRC Press: Boca Raton, FL, USA, 2014.

7. World Health Organization. Ambient (Outdoor) Air Quality and Health Fact Sheet No 313; World Health Organization: Geneva, Switzerland, 2014; Updated in May 2018.

8. Rocklöv, J.; Forsberg, B.; Ebi, K.; Bellander, T. Susceptibility to mortality related to temperature and heat and cold wave duration in the population of Stockholm County, Sweden. Glob. Health Action 2014, 7, 22737. [CrossRef] [PubMed]

9. Estrada, F.; Botzen, W.W.; Tol, R.S. A global economic assessment of city policies to reduce climate change impacts. Nat. Clim. Chang. 2017, 7, 403. [CrossRef]

10. Smith, K.R.; Woodward, A.; Campbell-Lendrum, D.; Chadee, D.D.; Honda, Y.; Liu, Q.; Olwoch, J.; Revich, B.; Sauerborn, R.; Aranda, C.; et al. Human health: Impacts, adaptation and co-benefits. In Climate Change 2014: Impacts, Adaptation, and Vulnerability. Part A: Global and Sectoral Aspects. Contribution of Working Group II to the Fifth Assessment Report of the Intergovernmental Panel on Climate Change; Cambridge University Press: Cambridge, UK, 2017; pp. 709-754.

11. Kjellstrom, T.; Briggs, D.; Freyberg, C.; Lemke, B.; Otto, M.; Hyatt, O. Heat, human performance, and occupational health: A key issue for the assessment of global climate change impacts. Ann. Rev. Public Health 2016, 37, 97-112. [CrossRef]

12. Abel, D.W.; Holloway, T.; Harkey, M.; Meier, P.; Ahl, D.; Limaye, V.S.; Patz, J.A. Air-quality-related health impacts from climate change and from adaptation of cooling demand for buildings in the eastern United States: An interdisciplinary modeling study. PLoS Med. 2018, 15, e1002599. [CrossRef]

13. Wang, Y.; Chen, L.; Kubota, J. The relationship between urbanization, energy use and carbon emissions: Evidence from a panel of Association of Southeast Asian Nations (ASEAN) countries. J. Clean. Prod. 2016, 112, 1368-1374. [CrossRef]

14. Taslim, S.; Parapari, D.M.; Shafaghat, A. Urban design guidelines to mitigate Urban Heat Island (UHI) effects in hot-dry cities. J. Teknol. 2015, 74, 119-124. [CrossRef]

15. Kolokotsa, D.; Santamouris, M.; Zerefos, S.C. Green and cool roofs' urban heat island mitigation potential in European climates for office buildings under free floating conditions. Sol. Energy 2013, 95, 118-130. [CrossRef]

16. Priyadarsini, R. Urban heat island and its impact on building energy consumption In Advances in Building Energy Research; Routledge: Abingdon-on-Thames, UK, 2012.

17. Zinzi, M.; Agnoli, S. Cool and green roofs. An energy and comfort comparison between passive cooling and mitigation urban heat island techniques for residential buildings in the mediterranean region. Energy Build. 2012, 55, 66-76. [CrossRef]

18. Walcek, C.J.; Yuan, H.H. Calculated influence of temperature-related factors on ozone formation rates in the lower troposphere. J. Appl. Meteorol. 1995, 34, 1056-1069. [CrossRef]

19. Taha, H. Modeling the impacts of large-scale albedo changes on ozone air quality in the South Coast Air Basin. Atmos. Environ. 1997, 31, 1667-1676. [CrossRef]

20. Cohen, A.J.; Anderson, H.R.; Ostro, B.; Pandey, K.D.; Krzyzanowski, M.; Künzli, N.; Kersten Gutschmidt, C.; Arden Pope, I.R., III; Samet, J.M.; Smith, K.R. Urban air pollution. Comp. Quantif. Health Risks 2004, 2, 1353-1433.

21. Tan, P.Y.; bin Abdul Hamid, A.R. Urban ecological research in Singapore and its relevance to the advancement of urban ecology and sustainability. Landsc. Urban Plan. 2014, 125, 271-289. [CrossRef]

22. Corlett, R.T. Impacts of warming on tropical lowland rainforests. Trends Ecol. Evol. 2011, 26, 606-613. [CrossRef] [PubMed]

23. Chow, W.T.; Roth, M. Temporal dynamics of the urban heat island of Singapore. Int. J. Climatol. J. R. Meteorol. Soc. 2006, 26, 2243-2260. [CrossRef]

24. Mughal, M.O.; Li, X.X.; Yin, T.; Martilli, A.; Brousse, O.; Dissegna, M.A.; Norford, L.K. High-resolution, multi-layer modelling of Singapore's urban climate incorporating local climate zones. J. Geophys. Res. Atmos. 2019, 124, 7764-7785. [CrossRef]

25. Dos Santos, A.R.; de Oliveira, F.S.; da Silva, A.G.; Gleriani, J.M.; Gonçalves, W.; Moreira, G.L.; Juvanhol, R.S. Spatial and temporal distribution of urban heat islands. Sci. Total Environ. 2017, 605, 946-956. [CrossRef]

26. Chun, B.; Guldmann, J.M. Impact of greening on the urban heat island: Seasonal variations and mitigation strategies. Comput. Environ. Urban Syst. 2018, 71, 165-176. [CrossRef] 
27. Ruefenacht, L.; Acero, J.A. Strategies for Cooling Singapore: A Catalogue of 80+ Measures to Mitigate Urban Heat Island and Improve Outdoor Thermal Comfort; Cooling Singapore (CS): Singapore, 2017. [CrossRef]

28. Wong, N.H.; Cheong, D.W.; Yan, H.; Soh, J.; Ong, C.L.; Sia, A. The effects of rooftop garden on energy consumption of a commercial building in Singapore. Energy Build. 2003, 35, 353-364. [CrossRef]

29. Li, X.X.; Norford, L.K. Evaluation of cool roof and vegetations in mitigating urban heat island in a tropical city, Singapore. Urban Clim. 2016, 16, 59-74. [CrossRef]

30. Wong, N.H.; Tan, A.Y.K.; Tan, P.Y.; Wong, N.C. Energy simulation of vertical greenery systems. Energy Build. 2009, 41, 1401-1408. [CrossRef]

31. Wong, N.H.; Tan, A.Y.K.; Chen, Y.; Sekar, K.; Tan, P.Y.; Chan, D.; Wong, N.C. Thermal evaluation of vertical greenery systems for building walls. Build. Environ. 2010, 45, 663-672. [CrossRef]

32. Huang, G. $\mathrm{PM}_{2.5}$ opened a door to public participation addressing environmental challenges in China. Environ. Pollut. 2015, 197, 313-315. [CrossRef]

33. Zhang, L.; Fukuda, H.; Liu, Z. Households' willingness to pay for green roof for mitigating heat island effects in Beijing (China). Build. Environ. 2019, 150, 13-20. [CrossRef]

34. Zhang, L.; Fukuda, H.; Liu, Z. The value of cool roof as a strategy to mitigate urban heat island effect: A contingent valuation approach. J. Clean. Prod. 2019, 228, 770-777. [CrossRef]

35. Carlsson, F.; García, J.H.; Löfgren, Å. Conformity and the demand for environmental goods. Environ. Resource Econ. 2010, 47, 407-421. [CrossRef]

36. Ding, F.; Pang, H.; Guo, W. Impact of the urban heat island on residents' energy consumption: A case study of Qingdao. In IOP Conference Series: Earth and Environmental Science; IOP Publishing: Bristol, UK, 2018; Volume 121, p. 032026.

37. Chakraborty, T.; Hsu, A.; Manya, D.; Sheriff, G. Disproportionately higher exposure to urban heat in lower-income neighborhoods: A multi-city perspective. Environ. Res. Lett. 2019, 14, 105003. [CrossRef]

38. Macintyre, H.L.; Heaviside, C.; Taylor, J.; Picetti, R.; Symonds, P.; Cai, X.M.; Vardoulakis, S. Assessing urban population vulnerability and environmental risks across an urban area during heatwaves-Implications for health protection. Sci. Total Environ. 2018, 610, 678-690. [CrossRef] [PubMed]

39. Martin-Vide, J.; Sarricolea, P.; Moreno-García, M.C. On the definition of urban heat island intensity: The "rural" reference. Front. Earth Sci. Front. 2015, 3, 24. [CrossRef]

40. Liao, J.; Wang, T.; Wang, X.; Xie, M.; Jiang, Z.; Huang, X.; Zhu, J. Impacts of different urban canopy schemes in WRF/Chem on regional climate and air quality in Yangtze River Delta, China. Atmos. Res. 2014, 145, 226-243. [CrossRef]

41. Wang, Y.; Di Sabatino, S.; Martilli, A.; Li, Y.; Wong, M.S.; Gutiérrez, E.; Chan, P.W. Impact of land surface heterogeneity on urban heat island circulation and sea-land breeze circulation in Hong Kong. J. Geophys. Res. Atmos. 2017, 122, 4332-4352. [CrossRef]

42. Valdés, A.C.F. Influence of urban land cover on mexico city's meteorological conditions. In Proceedings of the NW-AIRQUEST 2018 Annual Meeting, Seattle, WA, USA, 13 June 2018; Available online: Http: //lar.wsu.edu/nw-airquest/docs/20180612_meeting/NWAQ_Valdez_20180613.pdf (accessed on 1 March 2020).

43. Stewart, I.D.; Oke, T.R. Local climate zones for urban temperature studies. Bull. Am. Meteorol. Soc. 2012, 93, 1879-1900. [CrossRef]

44. Bohnenstengel, S.I.; Evans, S.; Clark, P.A.; Belcher, S. Simulations of the London urban heat island. Q. J. R. Meteorol. Soc. 2011, 137, 1625-1640. [CrossRef]

45. Quah, E.; Mishan, E.J. Cost-Benefit Analysis; Routledge: New York, NY, USA, 2007.

46. Hanemann, W.M. Valuing the environment through contingent valuation. J. Econ. Perspect. 1994, 8, $19-43$. [CrossRef]

47. Lin, T.P.; De Dear, R.; Hwang, R.L. Effect of thermal adaptation on seasonal outdoor thermal comfort. Int. J. Climatol. 2011, 31, 302-312. [CrossRef]

48. Mitchell, R.C.; Carson, R.T. Using Surveys to Value Public Goods: The Contingent Valuation Method; Resources for the Future: Washington, DC, USA, 1989.

49. Soon, J.J.; Ahmad, S.A. Willingly or grudgingly? A meta-analysis on the willingness-to-pay for renewable energy use. Renew. Sustain. Energy Rev. 2015, 44, 877-887. [CrossRef]

50. Dupont, D.P. Do children matter? An examination of gender differences in environmental valuation. Ecol. Econ. 2004, 49, 273-286. [CrossRef] 
51. Carson, R. Contingent Valuation: A Comprehensive Bibliography and History; Edward Elgar Publishing: Cheltenham, UK, 2012.

52. Hanemann, M.; Loomis, J.; Kanninen, B. Statistical efficiency of double-bounded dichotomous choice contingent valuation. Am. J. Agric. Econ. 1991, 73, 1255-1263. [CrossRef]

53. Carson, R.T.; Flores, N.E.; Meade, N.F. Contingent valuation: Controversies and evidence. Environ. Resour. Econ. 2001, 19, 173-210. [CrossRef]

54. Lin, Y.; Wijedasa, L.S.; Chisholm, R.A. Singapore's willingness to pay for mitigation of transboundary forest-fire haze from Indonesia. Environ. Res. Lett. 2017, 12, 024017. [CrossRef]

55. Von Fintel, D. Dealing with earnings bracket responses in household surveys-How sharp are midpoint imputations? S. Afr. J. Econ. 2007, 75, 293-312. [CrossRef]

56. Cooper, J.C. Optimal bid selection for dichotomous choice contingent valuation surveys. J. Environ. Econ. Manag. 1993, 24, 25-40. [CrossRef]

57. Zsóka, Á.; Szerényi, Z.M.; Széchy, A.; Kocsis, T. Greening due to environmental education? Environmental knowledge, attitudes, consumer behavior and everyday pro-environmental activities of Hungarian high school and university students. J. Clean. Prod. 2013, 48, 126-138. [CrossRef]

58. Kaiser, F.G.; Fuhrer, U. Ecological behavior's dependency on different forms of knowledge. Appl. Psychol. 2003, 52, 598-613. [CrossRef]

59. Mobley, C.; Vagias, W.M.; DeWard, S.L. Exploring additional determinants of environmentally responsible behavior: The influence of environmental literature and environmental attitudes. Environ. Behav. 2010, 42, 420-447. [CrossRef]

60. Oğuz, D.; Kavas, S. Environmental awareness of university students in Ankara, Turkey. Afr. J. Agric. Res. 2010, 5, 2629-2636.

61. Kennedy, E.H.; Beckley, T.M.; McFarlane, B.L.; Nadeau, S. Why we don't "walk the talk": Understanding the environmental values/behaviour gap in Canada. Hum. Ecol. Rev. 2009, 16, 151-160.

62. Lopez-Feldman, A. Introduction to Contingent Valuation Using Stata; Centro de Investigacion y Docencia Economicas (CIDE): Toluca, Mexico, 2012.

63. Cameron, T.A.; Quiggin, J. Estimation using contingent valuation data from a "dichotomous choice with follow-up" questionnaire. J. Environ. Econ. Manag. 1994, 27, 218-234. [CrossRef]

64. Haab, T.C.; McConnell, K.E. Valuing Environmental and Natural Resources: The Econometrics of Non-Market Valuation; Edward Elgar Publishing: Cheltenham, UK, 2002.

65. Li, X.X.; Koh, T.Y.; Entekhabi, D.; Roth, M.; Panda, J.; Norford, L.K. A multi-resolution ensemble study of a tropical urban environment and its interactions with the background regional atmosphere. J. Geophys. Res. Atmos. 2013, 118, 9804-9818. [CrossRef]

66. Roth, M. Review of urban climate research in (sub) tropical regions. Int. J. Climatol. 2007, 27, $1859-1873$. [CrossRef]

67. Singapore Ministry of Finance, Singapore Budget 2020. Available online: https://www.singaporebudget.gov. sg/budget_2020 (accessed on 18 June 2020).

68. Krupnick, A. Mortality-risk valuation and age: Stated preference evidence. Rev. Environ. Econ. Policy 2007, 1, 261-282. [CrossRef]

69. Kotchen, M.J.; Boyle, K.J.; Leiserowitz, A.A. Willingness-to-pay and policy-instrument choice for climate-change policy in the United States. Energy Policy 2013, 55, 617-625. [CrossRef]

(C) 2020 by the authors. Licensee MDPI, Basel, Switzerland. This article is an open access article distributed under the terms and conditions of the Creative Commons Attribution (CC BY) license (http://creativecommons.org/licenses/by/4.0/). 